\title{
Evaluation of dust and trace metal estimates from the Community Multiscale Air Quality (CMAQ) model version 5.0
}

\author{
K. W. Appel ${ }^{1}$, G. A. Pouliot ${ }^{1}$, H. Simon ${ }^{2}$, G. Sarwar ${ }^{1}$, H. O. T. Pye ${ }^{1}$, S. L. Napelenok ${ }^{1}$, F. Akhtar ${ }^{3}$, and S. J. Roselle \\ ${ }^{1}$ Atmospheric Modeling and Analysis Division, National Exposure Research Laboratory, \\ Office of Research and Development, US Environmental Protection Agency, Research Triangle Park, North Carolina, USA \\ ${ }^{2}$ Air Quality Assessment Division, Office of Air Quality Planning and Standards, Office of Air and Radiation, \\ US Environmental Protection Agency, Research Triangle Park, North Carolina, USA \\ ${ }^{3}$ Heath and Environmental Impacts Division, Office of Air Quality Planning and Standards, Office of Air and Radiation, \\ US Environmental Protection Agency, Research Triangle Park, North Carolina, USA
}

Correspondence to: K. W. Appel (appel.wyat@epa.gov)

Received: 30 January 2013 - Published in Geosci. Model Dev. Discuss.: 7 March 2013

Revised: 10 May 2013 - Accepted: 31 May 2013 - Published: 4 July 2013

\begin{abstract}
The Community Multiscale Air Quality (CMAQ) model is a state-of-the-science air quality model that simulates the emission, transformation, transport, and fate of the many different air pollutant species that comprise particulate matter (PM), including dust (or soil). The CMAQ model version 5.0 (CMAQv5.0) has several enhancements over the previous version of the model for estimating the emission and transport of dust, including the ability to track the specific elemental constituents of dust and have the model-derived concentrations of those elements participate in chemistry. The latest version of the model also includes a parameterization to estimate emissions of dust due to wind action. The CMAQv5.0 modeling system was used to simulate the entire year 2006 for the continental United States, and the model estimates were evaluated against daily surface-based measurements from several air quality networks. The CMAQ modeling system overall did well replicating the observed soil concentrations in the western United States (mean bias generally around $\pm 0.5 \mu \mathrm{g} \mathrm{m}^{-3}$ ); however, the model consistently overestimated the observed soil concentrations in the eastern United States (mean bias generally between $0.5-1.5 \mu \mathrm{g} \mathrm{m}^{-3}$ ), regardless of season. The performance of the individual trace metals was highly dependent on the network, species, and season, with relatively small biases for $\mathrm{Fe}, \mathrm{Al}, \mathrm{Si}$, and $\mathrm{Ti}$ throughout the year at the Interagency Monitoring of Protected Visual Environments (IMPROVE) sites, while Ca, K, and $\mathrm{Mn}$ were overestimated and $\mathrm{Mg}$ underestimated. For the urban Chemical Speciation Network (CSN) sites, Fe, Mg,
\end{abstract}

and $\mathrm{Mn}$, while overestimated, had comparatively better performance throughout the year than the other trace metals, which were consistently overestimated, including very large overestimations of $\mathrm{Al}(380 \%)$, $\mathrm{Ti}(370 \%)$ and $\mathrm{Si}(470 \%)$ in the fall. An underestimation of nighttime mixing in the urban areas appears to contribute to the overestimation of trace metals. Removing the anthropogenic fugitive dust (AFD) emissions and the effects of wind-blown dust (WBD) lowered the model soil concentrations. However, even with both AFD emissions and WBD effects removed, soil concentrations were still often overestimated, suggesting that there are other sources of errors in the modeling system that contribute to the overestimation of soil components. Efforts are underway to improve both the nighttime mixing in urban areas and the spatial and temporal distribution of dust-related emission sources in the emissions inventory.

\section{Introduction}

Mineral dust (also referred to as soil) can represent a significant portion of the measured particulate matter (PM), both fine $\mathrm{PM}$ with a diameter less than $2.5 \mu \mathrm{m}\left(\mathrm{PM}_{2.5}\right)$ and coarse $\mathrm{PM}$ with a diameter less than $10 \mu \mathrm{m}\left(\mathrm{PM}_{10}\right)$. PM contributes to the deterioration of air quality and can lead to adverse health effects resulting in premature death (Dockery, 2009), degradation of pristine environments through reduced visibility (Malm et al., 1994) and radiation impacts by absorbing 
and/or reflecting solar radiation (Sokolik and Toon, 1996). As such, understanding the emission, transport and fate of dust in the environment is important for protecting human health and sensitive ecosystems, as well as assessing the impact of air quality on climate (e.g., surface temperature) due to radiative feedbacks from dust and PM.

The Community Multiscale Air Quality (CMAQ; Byun and Schere, 2006) model is a state-of-the-science air quality model capable of reproducing the emission, transformation, transport, and fate of the many different air pollutant species that comprise PM, including dust. The latest release of the CMAQ model, version 5.0 (CMAQv5.0), includes several enhancements over the previous version of the model (version 4.7; Foley et al., 2011) for estimating the emission and transport of dust. Specifically, the model now includes the ability to explicitly track the specific elemental constituents of dust (e.g., silicon, calcium, iron, etc.) and where applicable, have the model-derived concentration of those elements participate in the model chemistry. Previous versions of the model used prescribed "background" values for several elements and therefore did not represent the spatial and seasonal variations in the concentrations of those elements. The latest version of the model also includes a parameterization for estimating the emission of dust due to wind action (windblown dust; WBD). In addition, the emission inputs have been updated to include sources of anthropogenic fugitive dust (AFD), such as dust from unpaved roads and agricultural tilling, and the chemical boundary conditions (BCs) now include WBD from long-range transport.

In this study, the CMAQv5.0 model has been used to simulate the entire year 2006 for the continental United States (CONUS). The CMAQ model estimates of the trace elements comprising dust are evaluated against daily surface-based measurements of the same elements. In addition to the annual base simulation, several seasonal sensitivity simulations are performed in order to assess the impact that changes made to the emissions inventory, boundary conditions, and inclusion of the WBD mechanism have on the CMAQ model estimates of dust. Finally, several recommendations for further improving the CMAQ estimates of dust are discussed.

\section{Model inputs and configuration}

The CMAQ model requires inputs of gridded meteorological fields, emissions data, and boundary conditions. For a regional or continental CMAQ model simulation, the meteorological fields are typically provided by a regional scale meteorological model, such as the Weather Research and Forecast (WRF; Skamarock et al., 2008) model. The input emissions are typically derived from a standard emissions input database, such as the USEPA's National Emissions Inventory (NEI), for which base year inventories are available every three years. Finally, chemical boundary conditions are typically based off a larger, coarser CMAQ model simulation or from a hemispheric or global air quality simulation provided by a global chemistry model. The meteorological, emission, and boundary condition inputs used in the base CMAQ model simulation are described in this section.

\subsection{Meteorological inputs}

The meteorological inputs for the CMAQ model simulations were provided by a 2006 annual CONUS WRFv3.3 model simulation that utilized $12 \mathrm{~km}$ horizontal grid spacing and 35 vertical layers of variable thickness extending up to $50 \mathrm{hPa}$, with the top of the lowest model layer at approximately $20 \mathrm{~m}$ above ground level. Initial and boundary conditions for WRF were provided by the North American Mesoscale Model (NAM) available from the National Centers for Environmental Prediction. The WRF simulation utilized the Rapid Radiation Transfer Model Global (RRTMG) for long- and short-wave radiation (Iacono et al., 2008), the Kain-Fritsch 2 cumulus parameterization (Kain, 2004), the Morrison microphysics scheme (Morrison et al., 2009), the Pleim-Xiu land-surface model (PX-LSM; Xiu and Pleim, 2001; Pleim and Xiu, 1995), and the Asymmetric Convective Model version 2 (ACM2; Pleim, 2007a and b) planetary boundary layer (PBL) scheme.

Four-dimensional data assimilation (FDDA) was used to constrain the model above the PBL; however unlike previous WRF model simulations, no FDDA was used within the PBL, which results in an improved wind speed bias in the PBL as compared to WRF simulations that utilized FDDA throughout the troposphere (Gilliam et al., 2012). The raw WRF outputs were processed for the CMAQ model using version 4.0 of the Meteorology-Chemistry Interface Processor (MCIP; Otte and Pleim, 2010). A 10-day spin-up period was utilized to eliminate the effects of the initial conditions, while the simulation was run in 5- and half-day increments with $12 \mathrm{~h}$ overlaps between segments.

\subsection{Emission inputs}

\subsubsection{Base emissions}

The input emissions for the CMAQ model simulation are based on a $12 \mathrm{~km}$ national US domain with speciation for the Carbon-Bond 05 (CB05) chemical mechanism (Yarwood et al., 2005). The emission inventory and ancillary files were based on the 2005 NEI emission modeling platform (http://www.epa.gov/ttn/chief/net/ 2005inventory.html\#inventorydata). The fire emissions were based on 2006 daily fire estimates using the Hazard Mapping System fire detections and Sonoma Technology SMARTFIRE system (http://www.getbluesky.org/smartfire/ docs/Raffuse_2007.pdf). Continuous emission monitoring system (CEMS) data from 2006 was used for the electric generating units sector. Plume rise was calculated within the CMAQ model (in-line). Biogenic emissions were processed 
in-line in CMAQ and are based on the Biogenic Emissions Inventory System (BEIS) v3.14 (http://www.cmascenter. org). Mobile emissions were calculated for 2006 using the MOBILE6 vehicle emission modeling software (http://www. epa.gov/oms/m6.htm). For the remaining source sectors (i.e., area sources and non-EGU point sources) the emission estimates in the $2005 \mathrm{NEI}$ are the same as the 2002 version of the NEI. Wind-blown dust and lightning $\mathrm{NO}_{\mathrm{X}}\left(\mathrm{NO}+\mathrm{NO}_{2}\right)$ (Allen et al., 2012) were calculated using time-dependent input meteorology and observations from the National Lightning Detection Network (NLDN). The raw emissions inputs were preprocessed for the CMAQ model using the Sparse Matrix Operator Kernel Emissions (SMOKE; Houyoux et al., 2000).

\subsubsection{Anthropogenic fugitive dust emissions}

Crustal elements such as $\mathrm{Ca}$ and $\mathrm{Fe}$ are present in anthropogenic and wind-blown fugitive dust, but may also be found in some fly ash and industrial process emissions (which are chemically similar to crustal emissions). The sources of AFD include unpaved road dust, paved road dust, commercial construction, residential construction, road construction, agricultural tilling, livestock operations, and mining and quarrying. Unpaved road dust is the largest single emission category within the non-point fugitive dust category, accounting for about one-third of non-windblown fugitive dust emissions. This is followed in size by dust from tilling, quarrying, and other earthmoving. Source apportionment studies have shown that AFD emissions contribute on the order of 5-20\% of $\mathrm{PM}_{2.5}$ and $40-60 \%$ of $\mathrm{PM}_{10}$ in urban areas that either have been or potentially may be unable to attain the National Ambient Air Quality Standards (NAAQS) for $\mathrm{PM}_{2.5}$ and/or $\mathrm{PM}_{10}$ (Watson and Chow, 2000). Conversely, air quality models suggest vastly higher contributions from current fugitive dust emission inventories, with contributions ranging from 50 to $80 \%$ for $\mathrm{PM}_{2.5}$ and 70 to $90 \%$ for $\mathrm{PM}_{2.5}$ and/or $\mathrm{PM}_{10}$ (Watson and Chow, 2000). Although dust makes up the majority of PM emissions, much of the emitted mass gets deposited on surfaces near the source at scales much smaller than the model grid-cell resolution (Veranth et al., 2003; Etyemezian et al., 2004). This is not true of other sources that are either emitted at a higher elevation (e.g., power plant stacks) or are emitted in warm exhaust (e.g., from vehicles) that rises quickly and gets entrained into the air mass. To correct for the near-source removal of dust, emissions from these sources are typically multiplied by a transportable fraction as proposed by Pace (2005). This transportable fraction is applied on a per county basis to both $\mathrm{PM}_{10}$ and $\mathrm{PM}_{2.5}$.

$\mathrm{PM}_{2.5}$ emissions in the NEI are reported as an annual total. In order for these emissions to be used in modeling applications, they need to be chemically speciated and allocated to finer temporal resolutions (e.g., each hour of the year). $\mathrm{PM}_{2.5}$ emissions in the NEI are typically speciated into five chemical components (organic carbon (OC), elemental carbon
(EC), sulfate, nitrate, and other). Recently, an improved speciation of the PM has been developed to include, in addition to the current PM species, a range of trace metals as well as separate non-carbon organic matter and metal-bound oxygen (Reff et al., 2009). The current temporal profile used by the EPA to allocate dust emissions to daily resolution assumes no monthly variability and no weekday/weekend variation (http://www.epa.gov/ttn/chief/emch/index.html\#2005). In essence, each day is represented identically throughout the year. Additional, emissions from AFD sources are set to zero for any hour or in any grid cell when there is snow cover or when the soil is at least $50 \%$ saturated in the first $1 \mathrm{~cm}$ depth based on the soil types and saturation values in the PX-LSM.

In this work, three changes were made to improve and diagnose the fugitive dust emission estimates used in chemical transport modeling. The first change involves improvements to the transportable fraction applied to the gridded emission inventory field. Second, a new mapping of the temporal profiles is applied to fugitive dust emissions so that they vary by day of the year. Finally, the chemical speciation of $\mathrm{PM}_{2.5}$ emissions is updated based on Reff et al. (2009). This allows for better source attribution of the measured trace metals.

In Pace (2005), the transportable fraction, (i.e., the fraction of total mass that is not "captured" by near-source removal), is calculated on a per county basis for three regional planning organizations using the BEIS version 2 county-level land use information (Byun and Ching, 1999). To improve the transportable fraction in CMAQ, it was recalculated at a $1 \mathrm{~km}$ resolution using the newer BELD3 database (Vukovich and Pierce, 2002) for all of the CONUS using five broad land use categories (e.g., forest, urban, sparsely wooded and grass, agricultural, and barren/water), generally resulting in an increase in the transportable fraction in the western United States and little change to the transportable fraction in the eastern United States (Pouliot et al., 2010). Table 1 shows the mapping of the BELD3 land use types to the five broad land use categories and the associated capture fraction.

A second improvement to the emissions was to modify the temporal activity factors used in the emissions processing. For each of the fugitive dust source categories, revisions were made to the monthly, weekly, and daily temporal profiles. The rationale for these temporal allocation changes is that the activity factors for associated sectors differ from the activity factors that have previously been assumed for the fugitive dust emissions. For example, a flat daily profile had previously been used for agricultural tiling. This has now been replaced by the same temporal profile used for the combustion emissions from agricultural equipment in the non-road mobile source sector, which is a more realistic representation of the daily activity pattern for agricultural tilling. The temporal factors for each of the fugitive dust sectors have been harmonized with other components of the emission inventory and processing platform where appropriate (see http://www.epa. gov/ttn/chief/conference/ei19/session9/pouliot.pdf for additional details). 
Table 1. BELD3 categories, capture fraction class, and transportable fraction. Transportable fraction (ranging from 0 to 1 ) is defined as the fraction of total emitted PM mass that becomes entrained in the grid-cell mass.

\begin{tabular}{llr}
\hline BELD3 & Capture & $\begin{array}{r}\text { Transportable } \\
\text { Fraction }\end{array}$ \\
\hline USGS_urban & Uraction Class & 0.50 \\
USGS_drycrop & Grass & 0.75 \\
USGS_irrcrop & Grass & 0.75 \\
USGS_cropgrass & Grass & 0.75 \\
USGS_cropwdlnd & Grass & 0.75 \\
USGS_grassland & Grass & 0.75 \\
USGS_shrubland & Water/Barren & 1.00 \\
USGS_shrubgrass & Grass & 0.75 \\
USGS_savanna & Grass & 0.75 \\
USGS_decidforest & Forest & 0.05 \\
USGS_evbrdleaf & Forest & 0.05 \\
USGS_coniferfor & Forest & 0.05 \\
USGS_mxforest & Forest & 0.05 \\
USGS_water & Water/Barren & 1.00 \\
USGS_wetwoods & Forest & 0.05 \\
USGS_sprsbarren & Water/Barren & 1.00 \\
USGS_woodtundr & Grass & 0.75 \\
USGS_mxtundra & Water/Barren & 1.00 \\
USGS_snowice & Water/Barren & 1.00 \\
All Agriculture Classes & Grass & 0.75 \\
All Tree Classes & Forest & 0.05 \\
\hline & &
\end{tabular}

Finally, the speciation of $\mathrm{PM}_{2.5}$ emissions from all sources, including the dust sources, was updated. These updates to the speciation of $\mathrm{PM}_{2.5}$ were based on the work of Reff et al. (2009), in which an inventory for trace metals from $\mathrm{PM}_{2.5}$ was derived using EPA's SPECIATE database (EPA, 2006; Simon et al., 2010). Eighty-four composite $\mathrm{PM}_{2.5}$ profiles containing 37 trace elements were then created and mapped to all available source classification codes. In this work, we break down the miscellaneous component of $\mathrm{PM}_{2.5}$ (aka PMFINE) into 14 components for modeling in CMAQ. These 14 components are shown in Table 2 . The new speciation allows the emission inventory to be viewed in much more detail. For example, $89 \%$ of the Si inventory in the unadjusted 2002 NEI is dominated by six sources: agricultural tilling, unpaved road dust, external combustion boilers (from electric generating units), paved road dust, construction, and mining and quarrying.

\subsection{Chemical boundary conditions}

The chemical BCs for the CMAQ model simulation were provided by an annual 2006 GEOS-Chem (Bey et al., 2001) simulation. The GEOS-Chem simulation utilized the prepatch version 9-01-01 of the model with secondary organic aerosols enabled, and was run using $2.0^{\circ} \times 2.5^{\circ}$ (latitudelongitude) horizontal grid spacing and 24 vertical layers.
The simulation utilized GOES-5 meteorology and the default emissions based on the 2005 EPA NEI.

Since GEOS-Chem and CMAQ use different names and definitions for a number of species, it is necessary to map the GEOS-Chem species to the CMAQ species. GEOS-Chem uses the Dust Entrainment and Deposition (DEAD) scheme with GOCART source function (Zender et al., 2003; Ginoux et al., 2001; Fairlie et al., 2007) and transports WBD in four size bins with edges at $0.1,1,1.8,3.0$, and $6 \mu \mathrm{m}$ radii. For use in $\mathrm{BCs}$, the GEOS-Chem dust was speciated into trace metals as well as other lumped species based on a composite of four desert soil profiles from SPECIATE, with eight profiles (four for $\mathrm{PM}_{2.5}$ and four for $\mathrm{PM}_{10}$ ) of desert soil used to create a composite profile based on the median value for each species. Dust from GEOS-Chem (DST1-4) is mapped to CMAQ species by first matching the GEOS-Chem size bins to the CMAQ modes. Dust in the smallest GEOS-Chem size-bin (DST1) was matched to the CMAQ accumulation mode species ( $\mathrm{J}$ mode), while the three larger GEOS-Chem size bins (DST2-4) correspond to CMAQ's coarse mode (K mode). GEOS-Chem dust is speciated according to a composite (mean) profile. Table 3 provides a complete mapping of the CMAQ inorganic species to the GEOS-Chem tracer species.

\subsection{CMAQ model configuration}

The CMAQ model simulation utilized the latest version of the model (v5.0) available for download from the Community Modeling and Analysis System (CMAS) Center website (http://www.cmascenter.org/). The CMAQv5.0 model includes a number of improvements over the previous version of the model (v4.7.1), including an in-line photolysis calculation instead of look-up tables, a new condensed toluene mechanism for CB05 with chlorine chemistry (CB05TUCL), updated aerosol chemistry and speciation to include the detailed speciation profiles described in Sect. 2.2.2, a representation of contributions from WBD, inclusion of NO emissions from lightning, an updated turbulent mixing scheme under stable conditions and an improved vertical advection scheme, as well as a number of additional updates to the model code structure. For additional details regarding the new features and enhancements in CMAQv5.0, the reader is referred to the release notes available for download along with the CMAQ model code.

The CMAQ model simulation covers the CONUS and parts of southern Canada and northern Mexico using $12 \mathrm{~km}$ horizontal grid spacing and 35 vertical layers matched to the WRF vertical layer structure. The CMAQ model simulations performed for this work utilize the CB05TUCL chemical mechanism, the ACM2 PBL scheme, the Euler backward iterative (EBI) solver, in-line plume rise for point sources, and employ the optional in-line photolysis calculation and NO emissions from lightning. 
Table 2. The revised speciation of PMFINE and the reasons for making them explicit.

\begin{tabular}{lll}
\hline New Species & Description & Reason \\
\hline PH20 & $\begin{array}{l}\text { Particulate Water } \\
\text { Associated with } \\
\text { Ammonium Sulfate }\end{array}$ & Already an explicit secondary PM species in CMAQ, but not previously emitted directly \\
PCL & Chloride & Already an explicit secondary PM species in CMAQ, but not previously emitted directly \\
PNA & Sodium & Already an explicit secondary PM species in CMAQ, but not previously emitted directly \\
PNH4 & Ammonium & Already an explicit secondary PM species in CMAQ, but not previously emitted directly \\
PNCOM & Non-Carbon Organic & To accurately model total organic mass \\
& Matter & \\
PCA & Calcium & For modeling thermodynamic partitioning, and for crustal matter \\
PSI & Silicon & To represent crustal matter \\
PMG & Magnesium & For modeling thermodynamic partitioning \\
PMN & Manganese & For modeling aqueous sulfur reactions \\
PAL & Aluminum & To represent crustal matter \\
PFE & Iron & To represent crustal matter and for modeling aqueous sulfur oxidation reactions \\
PTI & Titanium & To represent crustal matter \\
PK & Potassium & For modeling thermodynamic partitioning \\
PMOTHR & Unspeciated PM PM.5 $_{2.5}$ Mass & Remaining part of PMFINE (renamed) \\
\hline
\end{tabular}

The two most important changes in the new version of the model that affect the estimates of dust are the updates to the aerosol chemistry and speciation, and the representation of the effects of WBD in the model. In addition, changes to turbulent mixing and vertical advection also affect how dust is dispersed and transported in the model.

Enhancements to the aerosol module in CMAQv5.0 were directed both at improving the aerosol chemistry as well as speciation. Evaluation studies have revealed that the largest biases in CMAQ $\mathrm{PM}_{2.5}$ results are driven by over predictions of the unspeciated $\mathrm{PM}_{2.5}$, referred to hereafter as $\mathrm{PM}_{\text {other }}$ (Appel et al., 2008); this component constitutes over half of the NEI for $\mathrm{PM}_{2.5}$ using the old five-component chemical speciation scheme. Detailed speciation profiles derived from the work of Reff et al. (2009) were used to further subdivide emissions of $\mathrm{PM}_{\mathrm{other}}$ into primary ammonium $\left(\mathrm{NH}_{4}^{+}\right)$, sodium $\left(\mathrm{Na}^{+}\right)$, chloride $\left(\mathrm{Cl}^{-}\right)$, selected trace metals $(\mathrm{Mg}$, $\mathrm{Al}, \mathrm{Si}, \mathrm{K}, \mathrm{Ca}, \mathrm{Ti}, \mathrm{Mn}$, and $\mathrm{Fe}$ ), and non-carbon organic mass (NCOM).

The CMAQ transport and chemistry operators were further modified to explicitly represent these nine additional PM constituents. This additional speciation now allows for detailed characterization of the species, processes, and emission sector contributions to the model bias in primary and consequently total PM. The explicit treatment of Fe and Mn also allows for explicit representation of their catalysis effects on $\mathrm{S}(\mathrm{IV})$ to $\mathrm{S}(\mathrm{VI})$ conversion through aqueous chemistry, and consequently more consistent treatment of sulfate $\left(\mathrm{SO}_{4}^{2-}\right)$ production pathways in the model.

The representation of gas/particle partitioning of chloride, ammonia, and nitrate was also improved through the incorporation of ISORROPIA version II (ISORROPIA II; Fountoukis and Nenes, 2007; Nenes et al., 1998, 1999).
In addition to more robust solutions compared to previous versions of ISORROPIA, ISORROPIA II includes calcium $\left(\mathrm{Ca}^{2+}\right)$, potassium $\left(\mathrm{K}^{+}\right)$, and magnesium $\left(\mathrm{Mg}^{2+}\right)$ ions, species abundant in sea salt and soil dust, which can affect the partitioning of semivolatile inorganic species. The explicit representation of dust emission and PM composition simulated by CMAQv5.0 facilitates the expanded speciation and incorporation of ISORROPIA II.

In previous versions of CMAQ, contributions of natural WBD on airborne PM mass were not explicitly represented. CMAQv5.0 includes a module that dynamically estimates natural emissions of fine and coarse dust particles due to wind action over arid and agricultural land. To accurately estimate WBD emissions and the downwind effects on air quality, several processes have to be resolved, including identifying the locations of sources, estimating the magnitude of the dust emissions under various atmospheric and soil conditions, and finally predicting the resulting downwind air quality. Parameters that influence the dust emission process include the following: (1) the specification of locations that have the capacity to emit WBD and the erodibility of the soil in those locations, (2) the estimate of the horizontal sediment flux and resulting vertical transport of dust, (3) the shear stress (the threshold friction velocity) for various soil types, (4) adjustments of threshold velocity by roughness partition, (5) soil moisture, (6) the size distributions of emitted dust particles, and (7) the chemical speciation of emitted dust particles. 
Table 3. GEOS-Chem to CMAQ boundary condition mapping for dust and inorganic aerosol species. SALA and SALC represent accumulation and coarse sea salt in GEOS-Chem. SO4s and NITs are sulfate and nitrate formed on sea-salt aerosol. OCPI and OCPO are primary organic carbon in GEOS-Chem.

\begin{tabular}{|c|c|}
\hline CMAQ Species & GEOS-Chem Tracer \\
\hline \multicolumn{2}{|c|}{ Coarse-mode aerosol } \\
\hline ASO4K & $0.0776 \times \mathrm{SALC}+0.02655 \times(\mathrm{DST} 2+\mathrm{DST} 3+\mathrm{DST} 4)+\mathrm{SO} 4 \mathrm{~s}$ \\
\hline ANO3K & $\mathrm{NITs}+0.0016 \times(\mathrm{DST} 2+\mathrm{DST} 3+\mathrm{DST} 4)$ \\
\hline ACLK & $0.5538 \times \mathrm{SALC}+0.01190 \times(\mathrm{DST} 2+\mathrm{DST} 3+\mathrm{DST} 4)$ \\
\hline ASOIL & $0.95995 \times(\mathrm{DST} 2+\mathrm{DST} 3+\mathrm{DST} 4)$ \\
\hline \multicolumn{2}{|c|}{ Accumulation-mode aerosol } \\
\hline ASO4J & $0.99 \times \mathrm{SO} 4+0.0776 \times \mathrm{SALA}+0.0225 \times(\mathrm{DST} 1)$ \\
\hline ANO3J & $0.99 \times \mathrm{NIT}+0.00020 \times(\mathrm{DST} 1)$ \\
\hline ACLJ & $0.5538 \times \mathrm{SALA}+0.00945 \times(\mathrm{DST} 1)$ \\
\hline ANH4J & $0.99 \times \mathrm{NH} 4+0.00005 \times(\mathrm{DST} 1)$ \\
\hline ANAJ & $0.3086 \times \mathrm{SALA}+0.03935 \times(\mathrm{DST} 1)$ \\
\hline ACAJ & $0.0118 \times$ SALA $+0.07940 \times(\mathrm{DST} 1)$ \\
\hline AKJ & $0.0114 \times$ SALA $+0.03770 \times(\mathrm{DST} 1)$ \\
\hline APOCJ & $0.999 \times(\mathrm{OCPI}+\mathrm{OCPO})+0.01075 \times(\mathrm{DST} 1)$ \\
\hline APNCOMJ & $0.4 \times 0.999 \times(\mathrm{OCPI}+\mathrm{OCPO})+0.0043 \times(\mathrm{DST} 1)$ \\
\hline AFEJ & $0.03355 \times(\mathrm{DST} 1)$ \\
\hline AALJ & $0.05695 \times(\mathrm{DST} 1)$ \\
\hline ASIJ & $0.19435 \times(\mathrm{DST} 1)$ \\
\hline ATIJ & $0.0028 \times(\mathrm{DST} 1)$ \\
\hline AMNJ & $0.00115 \times(\mathrm{DST} 1)$ \\
\hline AOTHRJ & $0.50219 \times(\mathrm{DST} 1)$ \\
\hline AMGJ & $0.0368 \times$ SALA \\
\hline \multicolumn{2}{|c|}{ Aitken-mode aerosol } \\
\hline ASO4I & $0.01 \times \mathrm{SO} 4$ \\
\hline ANO3I & $0.01 \times \mathrm{NIT}$ \\
\hline ANH4I & $0.01 \times \mathrm{NH} 4$ \\
\hline APOCI & $0.001 \times(\mathrm{OCPI}+\mathrm{OCPO})$ \\
\hline APNCOMI & $0.4 \times 0.001 \times(\mathrm{OCPI}+\mathrm{OCPO})$ \\
\hline
\end{tabular}

\section{Observation data}

There are several sources of routine, ground-based observations of PM that include observations of the speciated dust components. Both the Interagency Monitoring of Protected Visual Environments (IMPROVE; http://vista.cira.colostate. edu/improve/) and Chemical Speciation (CSN; http://www. epa.gov/ttnamti1/speciepg.html) networks provide surface measurements of total $\mathrm{PM}_{2.5}$ and $\mathrm{PM}_{10}$, along with speciated $\mathrm{PM}_{2.5}$ measurements of $\mathrm{SO}_{4}^{2-}, \mathrm{NO}_{3}^{-}, \mathrm{NH}_{4}^{+}, \mathrm{Na}^{+}, \mathrm{Cl}^{-}$, and the trace metals of $\mathrm{Mg}, \mathrm{Al}, \mathrm{Si}, \mathrm{K}, \mathrm{Ca}, \mathrm{Ti}, \mathrm{Mn}$, and $\mathrm{Fe}$. The IMPROVE network consisted of 161 sites in 2006, with the majority of the sites located in the western United States. The IMPROVE network sites are typically located in rural areas, with a large number of the sites located in national parks, and as such the measurements tend to represent the background concentration of pollutants. Conversely, the CSN network consisted of 214 sites in 2006, primarily located in urban areas, with a larger majority of the sites located in the eastern United States. In addition to data from the IMPROVE and CSN networks, the Clean Air Status and Trends Network (CASTNET) provides weekly average measurements of particulate $\mathrm{SO}_{4}^{2-}, \mathrm{NO}_{3}^{-}, \mathrm{NH}_{4}^{+}$, and $\mathrm{HNO}_{3}$, along with gaseous $\mathrm{SO}_{2}$. There were 85 active CASTNET sites in 2006.

Measurements at IMPROVE and CSN sites are typically made every third day as $24 \mathrm{~h}$ averages. The measurements from each network are paired in time and space with the CMAQ model estimates using the Atmospheric Model Evaluation Tool (AMET; Appel et al., 2011). The pairing is done without any interpolation of the model value to its location within the grid (a simple grid value to measurement value matching is used), and therefore the analysis presented is subject to the inherent incommensurability issues that arise when comparing model grid-cell-averaged values to point measurements (Swall and Foley, 2009). Note that measurements that fall within the same grid cell are not averaged together but instead paired individually to the same grid-cell value. 
Soil is not directly measured at the IMPROVE and CSN sites but instead is derived from measurements of the various trace metals at each monitoring site (Eq. 1). The soil equation is a useful aggregate measure of soil (as it could be tedious to examine each individual element separately). This equation was first developed by Malm et al. (1994), and accounts for mass associated with oxidized forms of aluminum, silicon, calcium, iron, and titanium. In addition, the multiplication factors for each of these elements accounts for additional mass associated with soil organic matter, potassium, and other compounds. This soil equation has been used to calculate soil contributions to visibility degradation for the purpose of complying with the US EPA's regional haze rule at IMPROVE monitoring locations (http://vista.cira.colostate.edu/improve/publications/ graylit/023_SoilEquation/Soil_Eq_Evaluation.pdf). In this work, we define soil by applying Eq. (1) to measured data from IMPROVE and CSN networks, as well as to the CMAQ model data.

$$
\begin{aligned}
\text { Soil } & =(2.20 \times \mathrm{Al})+(2.49 \times \mathrm{Si})+(1.63 \times \mathrm{Ca})+ \\
& (2.42 \times \mathrm{Fe})+(1.94 \times \mathrm{Ti})
\end{aligned}
$$

The measurements of soil from both IMPROVE and CSN are for the fine $\left(\mathrm{PM}_{2.5}\right)$ fraction of PM only. Any difference in comparing these measurements to the sum of the Aitken $(i)$ and accumulation $(j)$ modes from CMAQ is likely to be small overall, but could be more substantial in some instances.

A recent study by Indresand and Dillner (2012) showed that $\mathrm{Si}$ and $\mathrm{Al}$ measurements from the IMPROVE network are misreported when the sulfur to iron $(\mathrm{S} / \mathrm{Fe})$ ratio is large. This is due to low-energy spectral interference by $\mathrm{S}$ in the $\mathrm{X}$ ray fluorescence spectrometry (XRF) instrument used for the IMPROVE sites. They examined IMPROVE data from 2008 and found that when the observed $\mathrm{S} / \mathrm{Fe}$ ratio was less than 8, which constituted $49 \%$ of the data, the reported $\mathrm{Si}$ and $\mathrm{Al}$ value were not affected by the $\mathrm{S}$ interference. For $\mathrm{S} / \mathrm{Fe}$ ratios greater than 8 but less than 70 (47\% of the data), the $\mathrm{Si}$ value was overreported by up to $100 \%$ and the $\mathrm{Al}$ value was either overreported by $50 \%$ or incorrectly reported as below detection limit. For S / Fe ratios greater than 70 (4\% of the data), the Si value was overreported by a factor of 2 or more, while the $\mathrm{Al}$ value was misreported by $\pm 50 \%$ or more. They advise using the IMPROVE Si and Al data cautiously when the $\mathrm{S} / \mathrm{Fe}$ ratio is large (while those data are included in the analysis here, no strong conclusions are made based on those particular data). The CSN measurements do not suffer from the same issue as the IMPROVE measurements due to lower measured $\mathrm{S}$ concentrations (due to a lower flow rate) and better peak baseline separation between $\mathrm{S}, \mathrm{Si}$, and $\mathrm{Al}$.

In addition to the potential issue with $\mathrm{Al}$ and $\mathrm{Si}$ measurements from the IMPROVE network, a separate analysis performed comparing soil measurements from IMPROVE and CSN sites revealed relative biases of up to $30 \%$ or more in
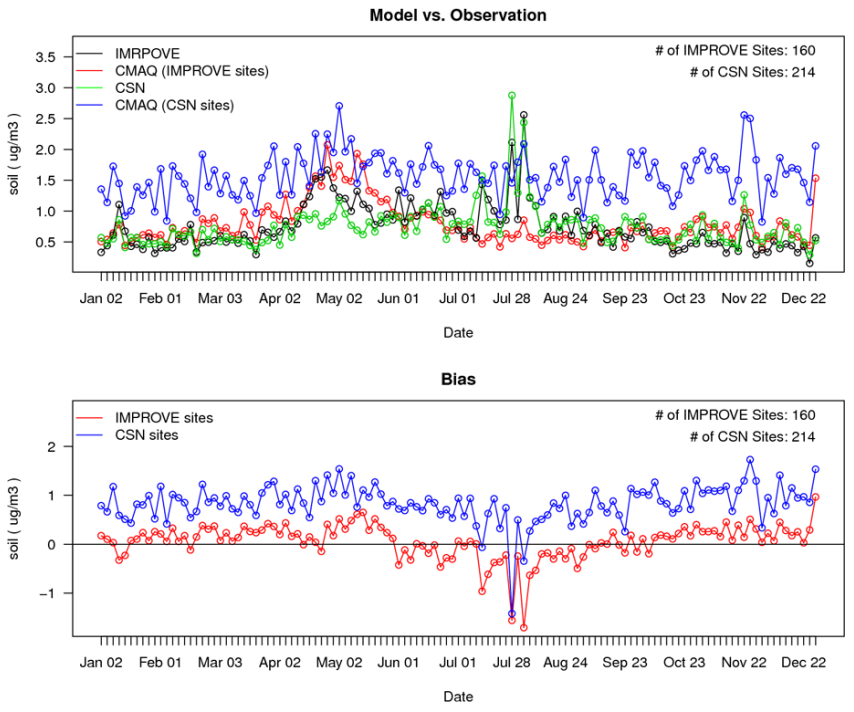

Fig. 1. The top time series plot shows the IMPROVE fine particulate soil observations (black) versus CMAQ estimated soil (red) and CSN soil observations (green) versus CMAQ estimated soil (blue) for 2006 for all CONUS sites. The bottom time series plot shows the CMAQ bias for soil at the IMPROVE network sites (red) and CSN sites (blue). Both plots are in units of $\mu \mathrm{g} \mathrm{m}^{-3}$.

the IMPROVE measurements, with higher IMPROVE concentrations (Hand et al, 2011). Furthermore, analyses of IMPROVE data suggest that $\mathrm{PM}_{2.5}$ soil mass concentrations may be underestimated by up to $20 \%$ and have some regional dependence (Malm and Hand, 2007). Finally, Solomon et al. (2004) found that IMPROVE measurements of $\mathrm{Fe}, \mathrm{Si}$, and Ca were biased slightly high compared to STN (CSN) measurements, an issue they contribute to potential difference in inlet cut-point efficiencies.

\section{CMAQ base model performance}

\subsection{Soil}

Figure 1 shows a time series of observed soil concentrations at the IMPROVE and CSN sites versus the CMAQ model estimates for the same network sites for all the CONUS sites. The observed soil concentrations are highest in the spring period (March-May), with a peak in concentrations in late April through early May. The observed soil concentrations at the IMPROVE and CSN sites tends to be comparable in magnitude, although in the spring the average concentration at the IMPROVE network sites is notably higher than the CSN sites, primarily due to relatively high concentrations of dust in the southwestern United States from the transported and WBD in that region. Note that there are relatively few CSN sites in the southwestern United States, while there are a large number of IMPROVE network sites in that region. 


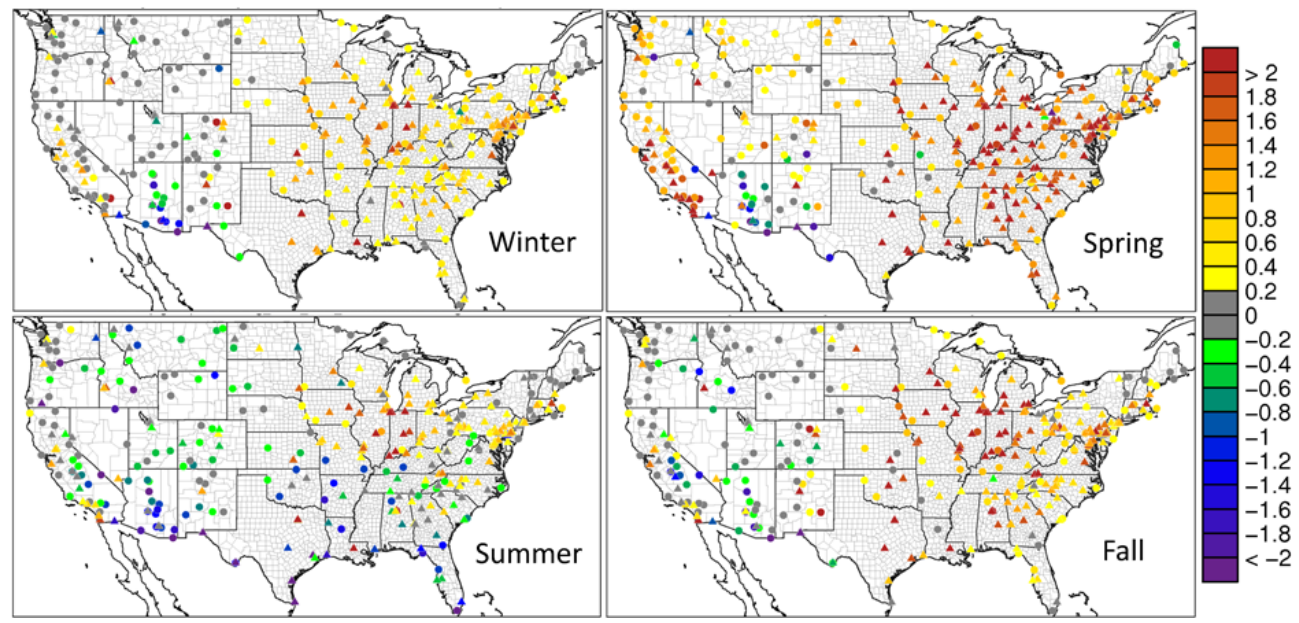

Fig. 2. Fine particulate soil seasonal mean bias $\left(\mu \mathrm{g} \mathrm{m}^{-3}\right.$ ) at the IMPROVE (circles) and CSN (triangles) network sites for the base CMAQ model simulation.

The CMAQ-model-estimated soil concentrations are in relatively good agreement with the IMPROVE network observations throughout the year, with a mean bias generally less than $\pm 0.5 \mu \mathrm{g} \mathrm{m}^{-3}$, with the exception of several episodes in the summer. For the CSN sites, the model systematically overestimates the soil concentrations throughout the year, again with the exception of several episodes in the summer when soil is underestimated. These results are generally consistent with the results presented by Tong et al. (2012) for a 2002 CMAQ model simulation, which reported mean biases of $0.3 \mu \mathrm{g} \mathrm{m}^{-3}$ and $1.2 \mu \mathrm{g} \mathrm{m}^{-3}$ for January and $-1.0 \mu \mathrm{g} \mathrm{m}^{-3}$ and $-0.6 \mu \mathrm{g} \mathrm{m}^{-3}$ for July for the IMPROVE and CSN networks, respectively.

Figure 2 presents a spatial plot of seasonal mean bias for soil for the IMPROVE and CSN sites. In the winter (December-February), the model shows a large difference in bias between the eastern and western United States, with sites in the eastern United States (east of the Rocky Mountains) showing a moderate to large overestimation (positive bias) in soil and sites in the western United States showing generally unbiased to slightly underestimated (negative bias) soil concentrations (exception being central California, where soil concentrations are overestimated). In the spring (March-May), soil is overestimated by the model at the vast majority of the IMPROVE and CSN network sites. Only sites in the southwest United States (i.e., Utah, Colorado, Arizona, and New Mexico) show unbiased to slightly underestimated soil concentrations. In the summer (June-August), the bias trend is reversed, with the majority of sites showing a slight to moderate $\left(1 \mu \mathrm{g} \mathrm{m}^{-3}\right.$ or less) underestimation of soil, the exception being in the Great Lakes region and small parts of the Northeast, where soil concentrations are still overestimated. In the fall (September-November), the bias pattern is very similar to the winter, with soil concentrations overestimated in the eastern United States and unbiased to slightly underestimated in the western United States. Similar spatial trends for the summer and winter were reported by Tong et al. (2012).

Overall, soil is consistently overestimated in the eastern United States throughout the year, while in the western United States, soil estimates tend to fluctuate between a slight underestimation to slight overestimation. Airborne soil in the eastern United States is primarily the result of anthropogenic sources, with a smaller contribution from natural WBD, whereas the western United States has a greater contribution to soil from WBD and long-range transport. Several possible reasons for the overestimation of dust in the eastern United States include AFD emissions that are too high in the model, an urban transportable fraction of dust that may be too large or too small, a contribution to soil from WBD that may be overestimated (should be small for eastern United States), and that the modeled PBL height in urban areas may be too low due to insufficient heat retention in urban areas (i.e., urban heat island effect). Several of these issues will be discussed further in Sect. 5. Additionally, the underestimation of soil in several areas for some time periods may be at least partially due to the wind-speed requirement in the current WBD implementation being too high, an issue that will be addressed in a future release of the model.

\subsection{Trace metals}

Figure 3 presents seasonal stacked bar plots of the observed and model-estimated concentrations of the trace metals Fe, $\mathrm{Al}, \mathrm{Ti}, \mathrm{Si}, \mathrm{Ca}, \mathrm{Mg}, \mathrm{K}$, and $\mathrm{Mn}$ from all the IMPROVE and CSN network sites. Note that the observed value of $\mathrm{Si}$ from IMPROVE is likely overestimated on average, while the Al measurement has a relatively large degree of uncertainty associated with it. Winter has the lowest seasonal total concentrations of both observed and modeled trace metals. The total concentration of all the trace metals in winter 


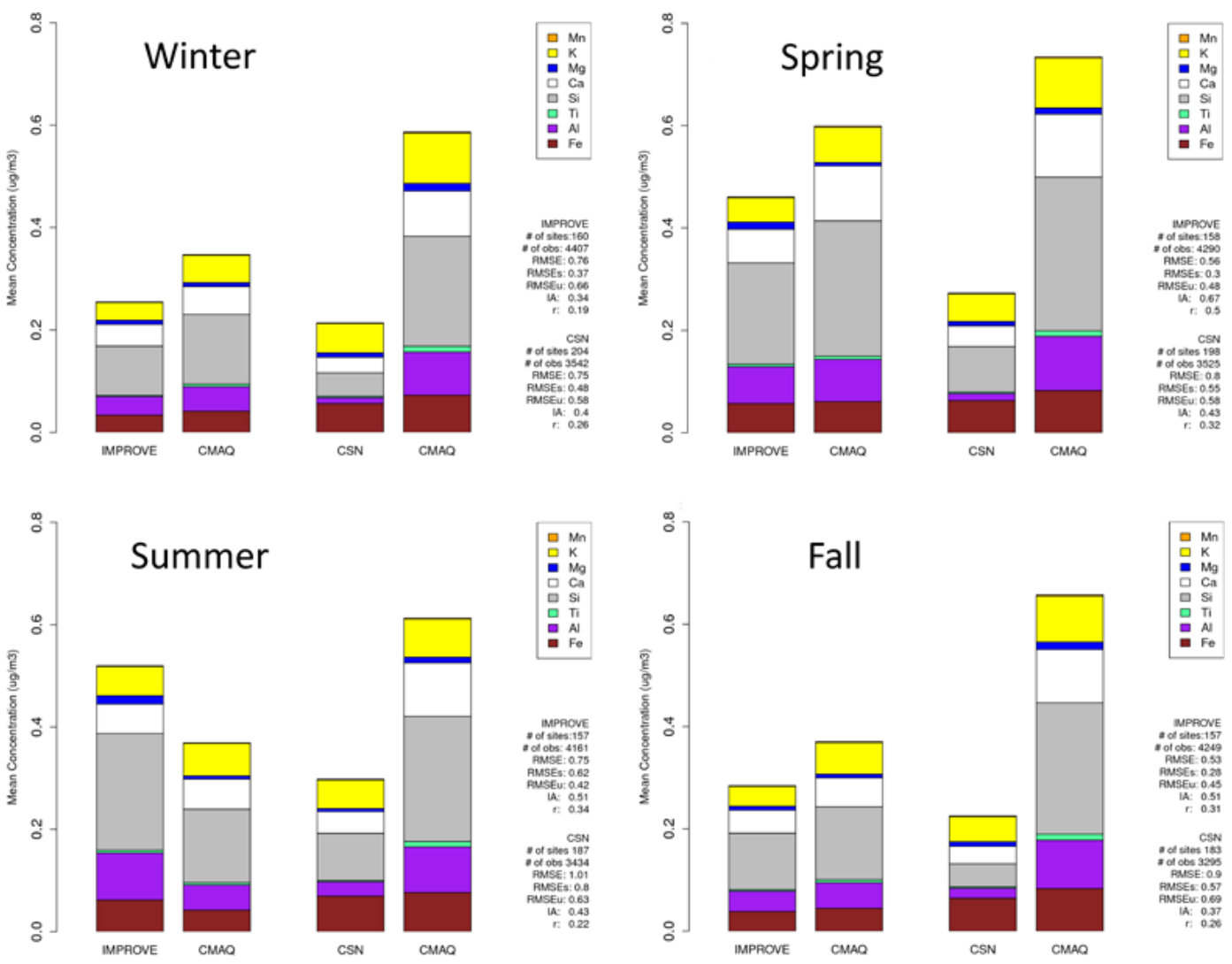

Fig. 3. Seasonal stacked bar plots of the observed concentrations $\left(\mu \mathrm{g} \mathrm{m}^{-3}\right)$ of the fine particulate trace metals $\mathrm{Fe}, \mathrm{Al}, \mathrm{Ti}, \mathrm{Si}, \mathrm{Ca}, \mathrm{Mg}, \mathrm{K}$, and Mn for the IMPROVE and CSN networks and the corresponding model-estimated concentrations. Shown below the legend on each plot are root-mean-square error (RMSE), index of agreement (IA), and correlation coefficient $(r$ ) for each network.

is overestimated by $\sim 40 \%$ for IMPROVE and $\sim 170 \%$ for CSN. For the IMPROVE network, $\mathrm{Fe}, \mathrm{Al}, \mathrm{Si}, \mathrm{Ca}, \mathrm{K}$, and $\mathrm{Mn}$ are overestimated by $20 \%$ to $60 \%$, while Ti is overestimated by $90 \%$ (the concentrations of $\mathrm{Ti}$ are very low however) and $\mathrm{Mg}$ is underestimated by $7 \%$. For the CSN, all the metals, with the exception of $\mathrm{Mg}$, are overestimated by at least $70 \%$, with $\mathrm{Al}, \mathrm{Ti}, \mathrm{Si}$, and $\mathrm{Ca}$ all overestimated by $\sim 200 \%$ or more. In the spring, the model performance is very similar to the winter, with the total concentration of all the trace metals overestimated by $30 \%$ for the IMPROVE network and $170 \%$ for the CSN. The performance of the individual trace metals is also similar, with most metals overestimated by 10 to $60 \%$ (Mg is underestimated by $50 \%$ ) for the IMPROVE network. The model continues to significantly overestimate $\mathrm{Al}, \mathrm{Ti}, \mathrm{Si}$, and Ca by $200 \%$ or more at the CSN sites $(\mathrm{Fe}, \mathrm{Mg}, \mathrm{K}$, and $\mathrm{Mn}$ are overestimated by 30 to $80 \%$ ).

In the summer, the total concentration of all the trace metals is underestimated by $30 \%$ for IMPROVE, but still overestimated by $50 \%$ for CSN. The largest underestimations for the IMPROVE network are in Fe (23\%), $\mathrm{Al}(47 \%), \mathrm{Si}$ (37\%), and $\mathrm{Mg}(61 \%)$, while $\mathrm{Ti}, \mathrm{Ca}, \mathrm{K}$, and $\mathrm{Mn}$ are all within $15 \%$ of the observed concentration. For the CSN, the largest overestimations are in $\mathrm{Al}(220 \%)$, $\mathrm{Ti}(297 \%)$,
Si $(165 \%)$, Ca (145\%), and $\mathrm{Mg}(92 \%)$, with smaller overestimations in $\mathrm{K}(32 \%)$ and $\mathrm{Mn}(48 \%)$, while $\mathrm{Fe}$ is within $10 \%$ of the observed concentration. In the fall, the total concentration of all the trace metals is again overestimated for both the IMPROVE (30\%) and CSN (190\%) networks. The overestimations at IMPROVE sites in fall are very similar to the winter, with the largest overestimations in $\mathrm{Ti}(83 \%), \mathrm{K}$ (59\%), and $\mathrm{Mn}(42 \%)$, smaller overestimations in $\mathrm{Fe}(16 \%)$, $\mathrm{Al}(27 \%), \mathrm{Si}(28 \%)$, and $\mathrm{Ca}(27 \%)$, and an underestimation in $\mathrm{Mg}(10 \%)$. For the CSN, the largest overestimations are in $\mathrm{Al}(380 \%)$, $\mathrm{Ti}(370 \%), \mathrm{Si}(470 \%)$, and $\mathrm{Ca}(206 \%)$, with smaller overestimations in $\mathrm{Fe}(28 \%), \mathrm{Mg}(62 \%), \mathrm{K}(84 \%)$, and $\mathrm{Mn}(16 \%)$. Time series plots for the individual trace metals can be found in the Supplement.

The large overestimation of trace metals at the urban CSN sites is at least in part due to an underestimation of nighttime mixing in the urban areas. An analysis of 615 hourly Mn and $\mathrm{Ca}$ measurements from a special observation site Dearborn, Michigan, from 13 July to 11 August 2007 (Pancras et al., 2013) is shown in Fig. 4, along with CMAQv5.0 model data for the same time period. What is clear from Fig. 4 is the large overestimation of $\mathrm{Mn}$ and $\mathrm{Ca}$ concentrations during the nighttime hours (the same trend is seen for the other 

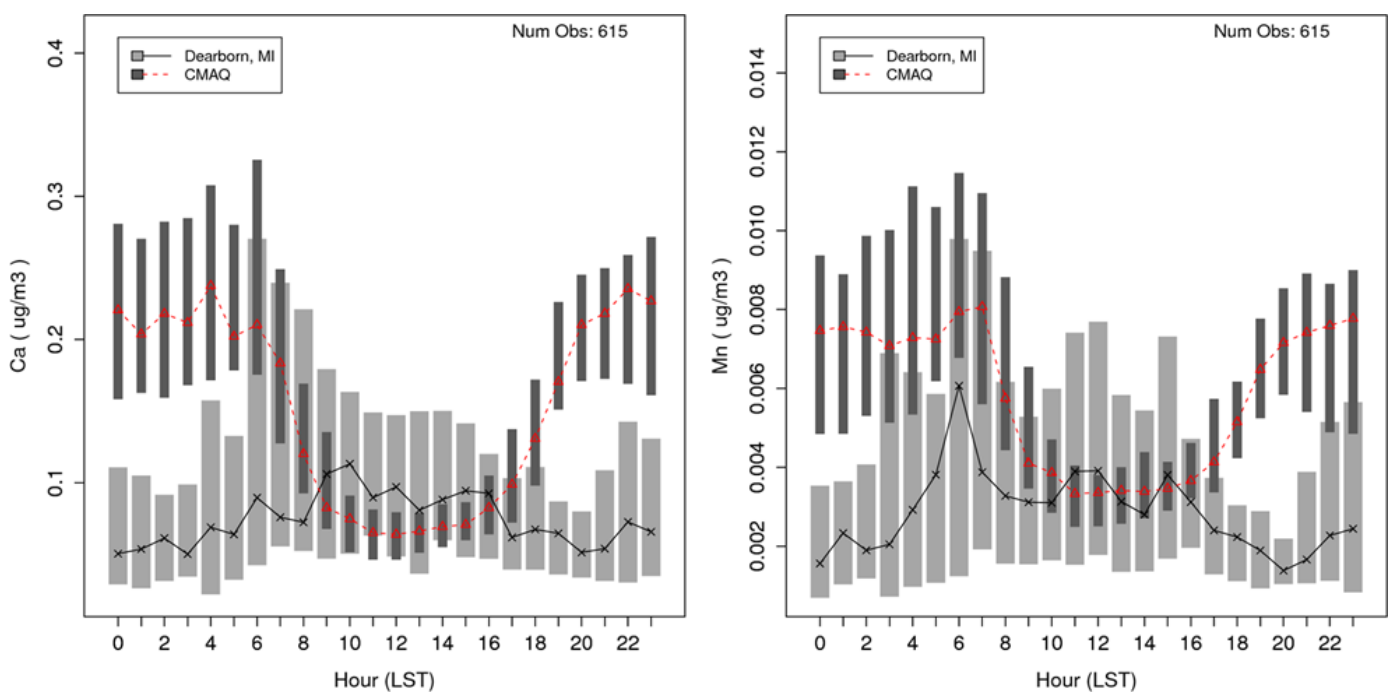

Fig. 4. Boxplots of observed (solid black; light shading) and CMAQ estimated (dashed red; dark shading) average diurnal concentrations $\left(\mu \mathrm{g} \mathrm{m}^{-3}\right)$ of $\mathrm{Mn}$ (left) and Ca (right) for Dearborn, Michigan, for 13 July-11 August 2007. The lines represent the median, while the shading represents the 25 th to 75 th (interquartile) range of the data.

trace metals). Similar overestimations have been observed in other primary emitted species (e.g., NO and $\mathrm{CO}$ ) in urban areas. This is due to the tendency of the WRF model to underestimate the overnight mixing in urban areas (Makar et al., 2006), possibly due to PBL heights that are too low or a minimum eddy diffusivity $\left(\mathrm{Kz}_{\min }\right)$ that is too small, which results in an overconcentration of pollutants near the surface, ultimately leading to high model biases. A number of the trace metals are emitted in urban areas from industrial operations that are continuous throughout the day and night. As such, those elements would tend to be overestimated during the night due to the insufficient mixing in the model. Work is currently underway to improve the nighttime mixing in urban areas by adding impervious surface information (e.g., pavement) into the WRF model in order to capture the heat retention in cities, which ultimately would improve the representation of mixing during stable conditions in these urban environments.

\subsection{Effect on sulfate chemistry}

In previous versions of the CMAQ model, aqueous-phase $\mathrm{SO}_{4}^{2-}$ production via the metal catalysis oxidation pathway was calculated using prescribed constant background concentrations of $0.01 \mu \mathrm{g} \mathrm{m}^{-3}$ for $\mathrm{Fe}(\mathrm{III})$ and $0.005 \mu \mathrm{g} \mathrm{m}^{-3}$ for $\mathrm{Mn}(\mathrm{II})$. As CMAQv5.0 contains predicted values of $\mathrm{Fe}$ and $\mathrm{Mn}$, these tracked concentrations are now used to estimate the $\mathrm{Fe}(\mathrm{III})$ and $\mathrm{Mn}(\mathrm{II})$ values for the metal catalyzed oxidation pathway. In addition to using model-estimated values of $\mathrm{Fe}$ and $\mathrm{Mn}$, the rate constant for in-cloud $\mathrm{SO}_{2}$ oxidation via metal catalysis was also updated in CMAQv5.0 following Martin and Good (1991). Previous versions of the model use the rate constant suggested by Walcek and Taylor (1986).
Alexander et al. (2009) implemented the reaction into a global chemical transport model and examined global implications of the sulfur budget. Sarwar et al. (2013) followed the procedures of Alexander et al. (2009) and implemented it into the CMAQ model. The new rate constant was developed at a $\mathrm{pH}$ of 3.0. Similar to Alexander et al. (2009), the new rate constant in CMAQv5.0 is used for all pH. Additional details regarding the implementation of the new treatment of crustal elements in the sulfate chemistry in CMAQ can be found in Sarwar et al. (2013).

Figure 5 presents spatial plots of the difference in monthly average particulate $\mathrm{SO}_{4}^{2-}$ between the CMAQv5.0 model simulation with the new crustal treatment and a simulation with the old treatment for January 2006. The $\mathrm{SO}_{4}^{2-}$ concentrations in January are much lower in the eastern US (where $\mathrm{SO}_{4}^{2-}$ concentrations are typically the highest) in the simulation with the new crustal treatment than in the one with the old treatment (Fig. 5a). The change in model performance for $\mathrm{SO}_{4}^{2-}$ in January as a result of the new crustal treatment is generally mixed, with some areas (e.g., southeast United States) showing a slight $\left(<1 \mu \mathrm{g} \mathrm{m}^{-3}\right)$ improvement in bias, while other areas (e.g., Great Lakes region) showing a slight increase in bias (Fig. 5b). In June (and summer in general), the difference in $\mathrm{SO}_{4}^{2-}$ concentrations is relatively small compared to January, with a mixture of very small increases and decreases in $\mathrm{SO}_{4}^{2-}$ concentrations over relatively small areas, and the change in $\mathrm{SO}_{4}^{2-}$ performance (bias) is minimal.

One reason that $\mathrm{SO}_{4}^{2-}$ concentrations decrease in the winter is that the calculated $\mathrm{Fe}$ (III) and Mn(II) in the CMAQv5.0 simulation are often lower than the prescribed $\mathrm{Fe}$ and $\mathrm{Mn}$ used in previous versions of the model. CMAQv5.0 uses the 

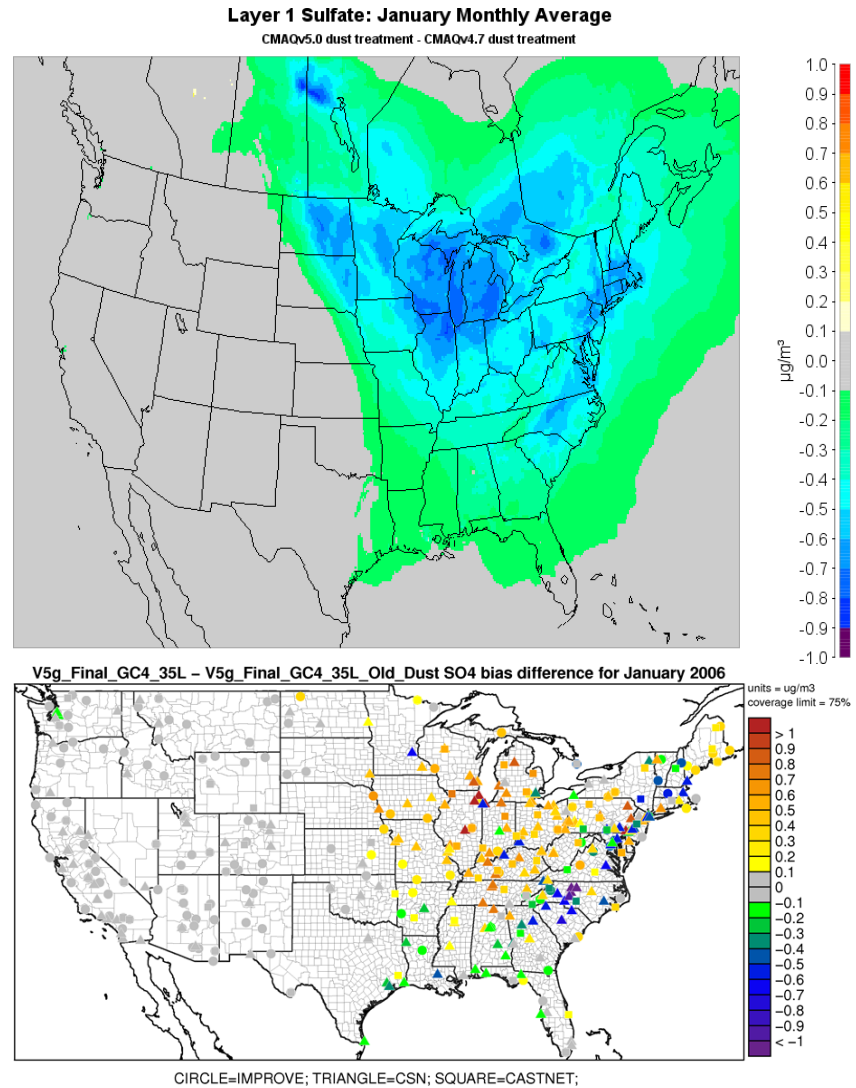

Fig. 5. (a) Difference in January monthly average $\mathrm{SO}_{4}{ }^{2-}$ concentrations $\left(\mu \mathrm{g} \mathrm{m}^{-3}\right)$ for the CMAQv5.0 base simulation and a CMAQ simulation with prescribed $\mathrm{Fe}$ and $\mathrm{Mn}$ values and the old rate constant. (b) Change in bias between the two CMAQ simulations at IMPROVE (circles), CSN (triangles), and CASTNET (squares) sites. Warm colors indicate an increase in bias in the base simulation, while cool colors indicate a decrease in bias.

predicted Fe and Mn concentrations and then applies solubility and oxidation state to calculate $\mathrm{Fe}(\mathrm{III})$ and $\mathrm{Mn}$ (II). In January, mean $\mathrm{Fe}(\mathrm{III})$ concentrations range from 0 to $0.07 \mu \mathrm{g} \mathrm{m}^{-3}$ and mean $\mathrm{Mn}(\mathrm{II})$ concentrations range from 0 to $0.06 \mathrm{\mu gm}^{-3}$ in the eastern US. However, the domain-wide monthly mean $\mathrm{Fe}$ (III) concentration in the same region is $0.003 \mu \mathrm{g} \mathrm{m}^{-3}$, which is three times lower than the prescribed constant value used in previous versions of the model. Similarly, the domain-wide monthly mean $\mathrm{Mn}(\mathrm{II})$ concentration is $0.0008 \mu \mathrm{g} \mathrm{m}^{-3}$, which is six times lower than the constant prescribed value used in the previous versions of the model.

The new rate constant can be higher or lower than the old rate constant, depending on the $\mathrm{pH}$. The impact of these changes on model-estimated $\mathrm{SO}_{4}^{2-}$ concentrations is small in the summer, as expected, since $\mathrm{SO}_{4}^{2-}$ production is predominantly due to oxidation by $\mathrm{H}_{2} \mathrm{O}_{2}$ and $\mathrm{OH}$. In winter, when the levels of these oxidants are lower, the contribution of the aqueous $\mathrm{Fe} / \mathrm{Mn}$ catalysis reaction pathway becomes important. As a result, the change from the old crustal

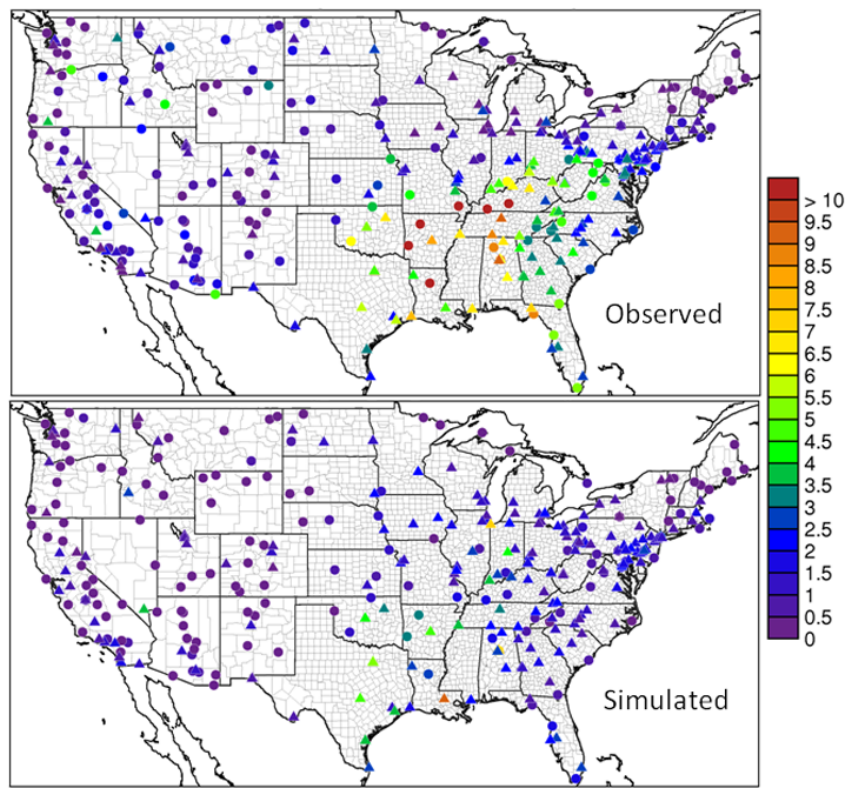

Fig. 6. Observed (top) and CMAQ simulated (bottom) average fine particulate soil concentrations $\left(\mu \mathrm{g} \mathrm{m}^{-3}\right)$ as estimated by the IMPROVE soil equation for 13 July, 28 July, and 4 August 2006. IMPROVE sites are indicated by circles; CSN sites are indicated by triangles.

treatment in CMAQv4.7 to the new treatment in CMAQv5.0 has the greatest impact on $\mathrm{SO}_{4}^{2-}$ concentrations in the winter. It should also be noted that the relatively good agreement between CMAQ and observed concentrations (Fig. 3) builds confidence in the ability to integrate these model-estimated concentrations into the CMAQ chemistry.

\subsection{Impact on soil concentrations from African dust events}

The time series in Fig. 1 shows several episodes in the summer where the model grossly underestimates the observed soil concentrations during high observed concentrations of soil at both the IMPROVE and CSN sites. Three distinct episodes of the high observed soil concentrations were identified to have occurred on 13 July, 28 July, and $3 \mathrm{Au}-$ gust 2006. Figure 6 presents spatial plots of observed and model simulated average soil concentrations from the three days identified above. The observed soil concentrations are highest in the southeastern United States, with observed concentrations greater than $4 \mu \mathrm{g} \mathrm{m}^{-3}$ (a number of sites having mean concentrations greater than $10 \mu \mathrm{g} \mathrm{m}^{-3}$ ) extending from Florida to central Texas, north into the Great Lakes region, and into the Northeast. While the CMAQ model estimates the highest soil concentrations in the same regions, most of the sites have mean concentrations less than $4 \mu \mathrm{g} \mathrm{m}^{-3}$, with only a few of the sites having mean concentrations above $4 \mu \mathrm{g} \mathrm{m}^{-3}$. The observed mean concentrations in the southeast United States for the three days are in strong contrast 
to the average mean observed soil concentration for July and August (not shown), which is typically less than $4 \mu \mathrm{g} \mathrm{m}^{-3}$ for the same region.

One possible cause of the high observed soil concentrations in July and August could be transported dust from the African continent, particularly from the Sahara region (Perry et al., 1997; Bates et al., 2008). In the summer, westerly flow in the subtropical region of the Northern Hemisphere can transport dust from the Sahara west across the Atlantic Ocean, sometimes reaching as far west as the CONUS. As these events are influence by dust from outside the CMAQ model domain, they need to be captured in the input BCs from GEOS-Chem. The GEOS-Chem model has demonstrated the ability to simulate the long-range transport of Saharan dust (Fairlie et al., 2007). Furthermore, an analysis aerosol optical depth (AOD) from satellite imagery, indicative of a dense concentration of particles in the troposphere, for late July and early August 2006 showed relatively high AOD values extending from Africa across the subtropical Atlantic Ocean to the east coast of the United States.

Figure 7 shows the average surface-level soil concentration from 25 July through 5 August 2006, which covers two of the three high soil concentration episodes in the eastern United States identified from Fig. 1. For the 12-day period, the GEOS-Chem-derived BCs capture high concentrations of soil (up to $20 \mu \mathrm{g} \mathrm{m}^{-3}$ ) along the southeastern boundary of the CMAQ model domain, which spread westward toward the CONUS. However, while the BC inputs include elevated soil concentrations, the high concentrations of soil do not progress far enough west to reach the eastern United States, with most of the soil being removed before it makes it to the coastal and inland areas (although some relatively high soil concentrations are observed in Florida).

One possible reason the high soil concentrations are not estimated correctly for the interior eastern United States may be due to an overestimation of convection and precipitation by the WRF model off the southeast coast of the United States and along the Gulf Stream, which results in excessive removal of dust by wet deposition. Figure 7 presents the WRF accumulated precipitation for the period of 25 July through 5 August 2006. The WRF model estimates for precipitation are large off the east coast of the United States, as well as in parts of the Caribbean, over Florida, and in the Gulf of Mexico. Unfortunately, little data exist with which to verify the precipitation estimates over the water (although some satellite-derived precipitation data are available, they were not examined here). However, Park et al. (2006) and Fairlie et al. (2007) note a similar underestimation of dust concentrations in Florida by the GEOS-Chem model due to excessive wet deposition (also the result of an overestimation of convective precipitation by the meteorological model).

Another reason for the lack of westward transport of the dust from the boundary may be due to incorrect wind flow or wind flow that is too weak off the southeast coast and in the Gulf of Mexico, which would result in the dust being
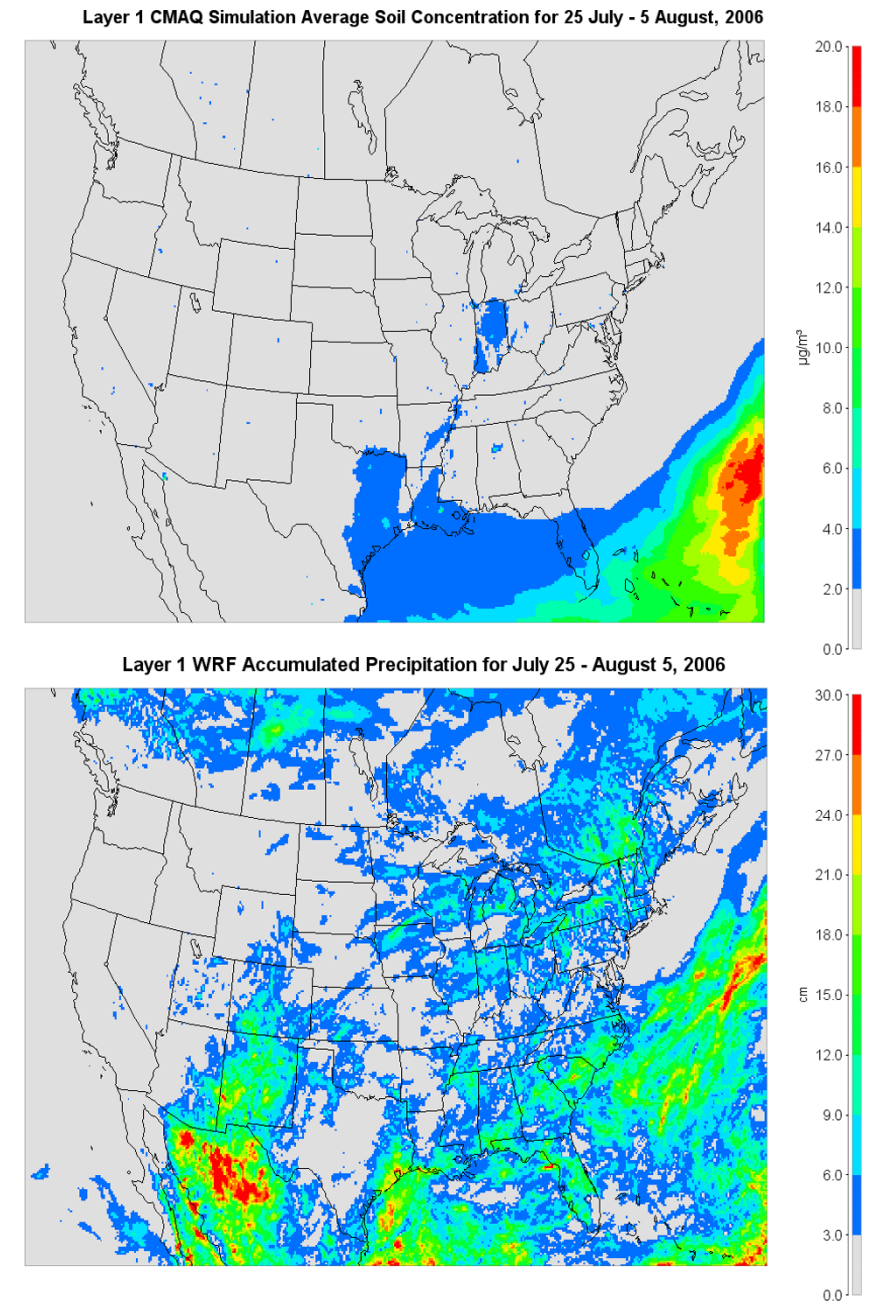

Fig. 7. Layer 1 CMAQ average soil concentration (top; $\mu \mathrm{g} \mathrm{m}^{-3}$ ) and WRF accumulated total precipitation (bottom; cm) for $25 \mathrm{July-}$ 5 August 2006.

advected in the wrong direction or settling out into the ocean before it reaches land. Additional sensitivity analyses with the WRF simulation are needed to confirm this as a possible cause of the transported dust issue within the CMAQ model simulation.

\section{CMAQ model sensitivities}

Several CMAQ model sensitivities were performed to further assess possible reasons for the noted discrepancies between modeled and observed trace element concentrations. Specifically, three separate model simulations were performed for the March through May time period, when observed soil concentrations are the highest, one with the emissions of anthropogenic fugitive dust removed, one with the WBD feature turned off, and one with both the AFD and WBD removed. These sensitivity simulations are compared to the base model 

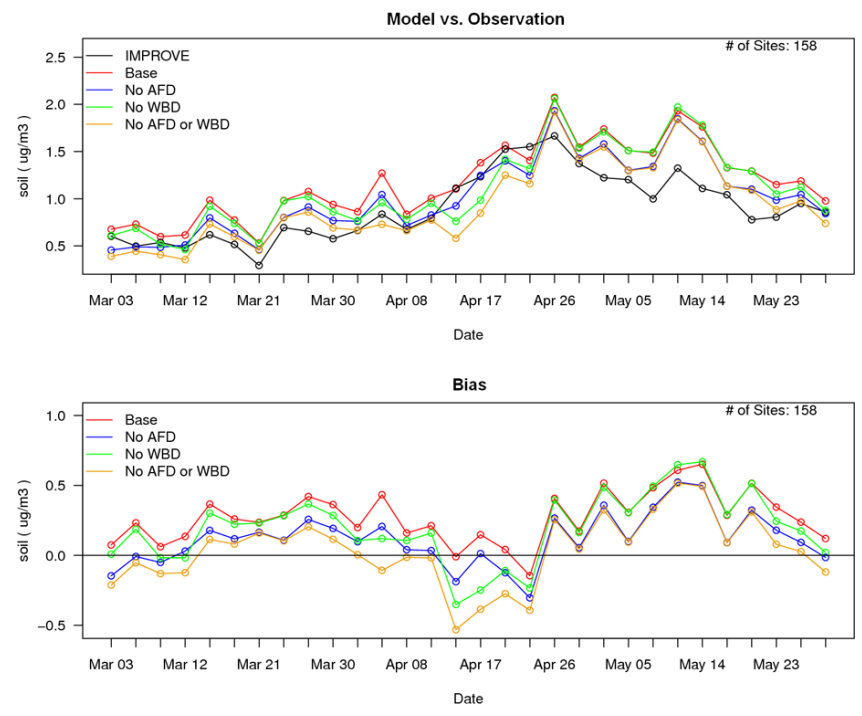

Fig. 8. Time series of IMPROVE-network-observed (black) and CMAQ-simulated soil concentrations ( $\mu \mathrm{g} \mathrm{m}^{-3}$; top) for the spring with the base CMAQ model simulation shown in red, the simulation with AFD emissions removed shown in blue, the simulation with WBD effects removed shown in green, and the simulation with both AFD emissions and the effects of WBD removed shown in orange. The bottom time series shows the corresponding mean bias $\left(\mu \mathrm{g} \mathrm{m}^{-3}\right)$ for the same model simulations.

simulation for the same time period, and the impact of each change on the model estimates is assessed.

\subsection{Effect of AFD emissions updates}

Figures 8 and 9 present time series of observed soil concentrations from the IMPROVE and CSN networks, respectively, and the corresponding model simulated soil concentrations for several CMAQ model sensitivities for the spring period. As noted previously in Fig. 1, the base CMAQ model simulation soil concentrations are slightly overestimated for most of the period compared to the observed soil concentrations from the IMPROVE network, with the largest overestimations from late April to late May. However, for the CSN, soil concentrations are typically overestimated by $1 \mu \mathrm{g} \mathrm{m}^{-3}$ or more for the entire period in the base simulation. The largest source of soil (trace metals) emissions in the emissions inventory (based on total soil emissions) is AFD (75\%), followed by electric generation units (EGUs; $13 \%$ ), industrial mineral processes $(2 \%)$, industrial fuel consumption ( $2 \%)$, and industrial metal production $(2 \%)$.

Figure 10 (top panel) shows the change in soil absolute bias as a result of removing the AFD emissions, with warm colors indicating the bias increased in the simulation with no AFD emissions, while cool colors indicate the bias decreased in the simulation with no AFD emissions. The seasonal average bias in soil decreases by between 0.1 and $0.7 \mu \mathrm{g} \mathrm{m}^{-3}$ in the eastern United States as a result of removing the AFD
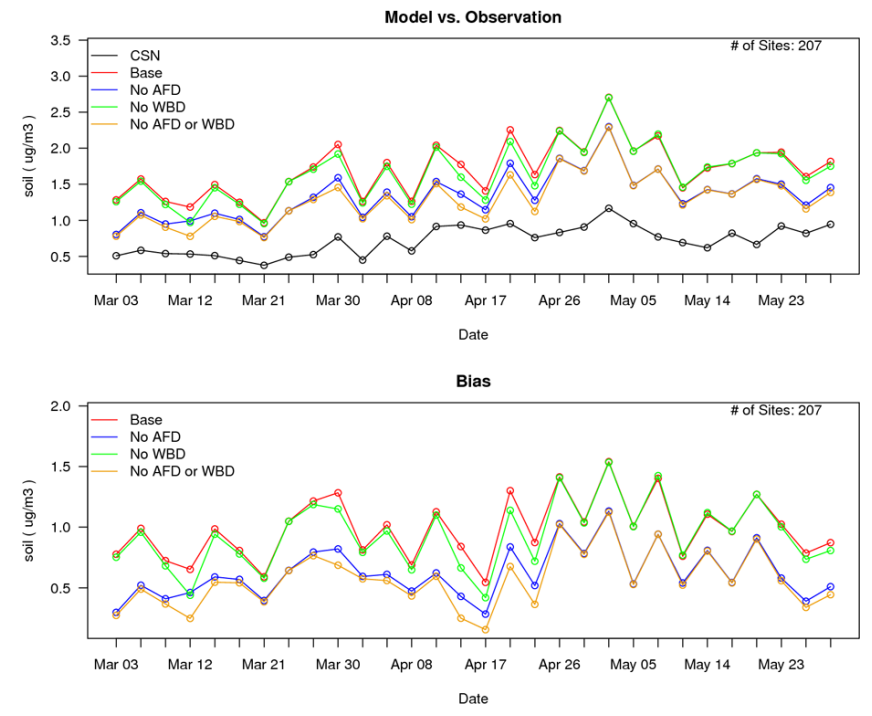

Fig. 9. Time series of CSN observed (black) and CMAQ simulated soil concentrations $\left(\mu \mathrm{g} \mathrm{m}^{-3}\right.$; top) for the spring with the base CMAQ model simulation shown in red, the simulation with AFD emissions removed shown in blue, the simulation with WBD effects removed shown in green, and the simulation with both AFD emissions and the effects of WBD removed shown in orange. The bottom time series shows the corresponding mean bias $\left(\mu \mathrm{g} \mathrm{m}^{-3}\right)$ for the same model simulations.

emissions, with the largest decrease in bias in the upper Midwest and Great Lakes regions. The bias increases slightly (between 0.1 and $0.5 \mu \mathrm{g} \mathrm{m}^{-3}$ ) in the southwestern United States in the simulation with AFD emissions removed, including increases in bias at sites in Texas and Oklahoma. Overall, removing the AFD emissions results in a large reduction in the soil bias in the eastern United States in the spring, suggesting there is an overestimation of the AFD emissions as well as likely issues with their diurnal temporal allocation.

\subsection{Effect of WBD mechanism}

The CMAQ model estimates for the simulation in which the effects of WBD were removed (NoWBD) are lower than the base-model-simulated soil concentrations but not as low as the simulation where AFD emissions were removed. The largest decrease in soil concentrations in the NoWBD simulation compared to the base simulation occur in the late March through mid-April period (Figs. 8 and 9), indicating the effects of WBD in the model are significant during that period. Conversely, there is very little difference between the base simulation and the NoWBD simulation from mid-April through the end of May, suggesting the WBD effects are small.

Figure 10 presents a spatial plot of the absolute change in bias between the base CMAQ simulation and the NoWBD simulation for the IMPROVE and CSN sites. Expectedly, the 


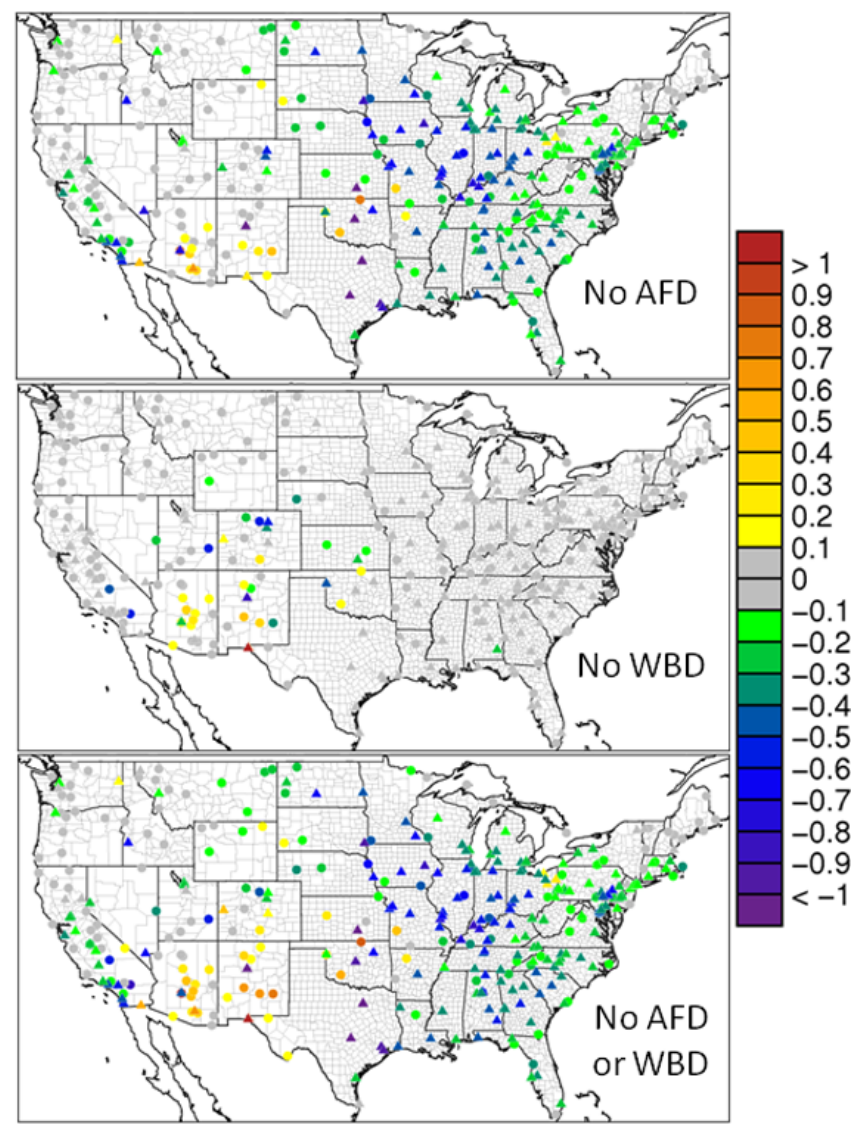

Fig. 10. Difference in average soil concentration bias $\left(\mu \mathrm{g} \mathrm{m}^{-3}\right)$ for spring (2006) between the CMAQ simulation with no AFD emissions and the base CMAQ simulation (No AFD - Base; top), the CMAQ simulation with no WBD and the base CMAQ simulation (No WBD - Base; middle), and the CMAQ simulation with no WBD or AFD emissions and the base CMAQ simulation (No AFD or WBD - Base; bottom). Circles indicate IMPROVE network sites and triangles indicate CSN sites.

largest impact on the model simulated soil concentrations occurs in the arid/semi-arid regions of the southwestern United States, with the bias slightly higher in the NoWBD simulation versus the base simulation. There is little to no impact to the bias in the eastern United States, where the bias in soil was highest in the base simulation (Fig. 2). These results suggest that an overestimation of WBD is not responsible for the high model-estimated soil concentrations in the eastern United States in the spring, where the effects of WBD should be small anyway.

\subsection{Effect of both AFD and WBD}

The final sensitivity performed removes the effects of both WBD and AFD emissions (referred to simply as NoDust) in order to assess the cumulative impact that those two updates to modeling system had on the model estimates of soil. The NoDust model simulation always has lower soil concentrations than the base simulation and the NoWBD simulation (Figs. 8 and 9). There are several days during which the effects of either the AFD emissions (e.g., 24 March) or WBD (e.g., 2 April) dominate the change in soil concentrations compared to the base simulation. In addition, soil concentrations are underestimated during the periods from 3 March to 12 March and 14 April to 23 April in the NoDust simulation, which are the only periods when soil is underestimated at the IMPROVE network sites (Fig. 8).

It is clear from the plots in Fig. 10 that the change in bias in the NoDust simulation is dominated by the removal of the AFD emissions, with the effect of removing WBD limited in time and space. Since AFD emissions and WBD should be nonzero, the result of improved model performance when those emissions are removed entirely suggests that there are other errors in the modeling system (e.g., emission inputs) that contribute to an overestimation of soil. Wind-blown dust generally constitutes a small, temporally and spatially localized contribution to the soil concentrations in the model, with the largest contribution to soil limited primarily to the spring period in the desert southwest of the United States (although small effects are seen throughout the year). The systematic overestimation of soil across most of the domain throughout the year, even when the AFD emissions are removed, suggests that other emissions of the trace elements in the soil equation are overestimated.

\section{Summary}

Mineral dust, or soil, can constitute a significant portion of observed airborne PM in the United States, especially in areas where agriculture and construction are prevalent, or in areas where WBD is common (e.g., southwest United States). The latest release of the CMAQ modeling system includes updated AFD emissions from agricultural farming and construction and the effects of WBD. To assess the CMAQ model estimates of soil and trace metals, an annual model simulation for the year 2006 was performed for the CONUS using the updated emissions inventory with AFD emissions and the effects of WBD included. The results of the model simulation were compared against ground-based observations of soil and trace metals from the IMPROVE and CSN networks.

The CMAQ modeling system generally did well replicating the observed soil concentrations in the western United States; however, the model consistently overestimated the observed soil concentration in the eastern United States, regardless of season. The performance for the individual trace metals is generally good at the IMPROVE network sites, with relatively small biases for $\mathrm{Fe}, \mathrm{Al}, \mathrm{Si}$, and $\mathrm{Ti}$ throughout the year, while $\mathrm{Ca}, \mathrm{K}$, and $\mathrm{Mn}$ tend to be overestimated and $\mathrm{Mg}$ underestimated. For CSN, Fe, Mg, and Mn, while overestimated, have relatively good performance throughout the year compared to the other metals, which are consistently 
overestimated, including very large overestimations of $\mathrm{Al}, \mathrm{Ti}$, and $\mathrm{Si}$ in the fall. The underestimation of nighttime mixing in the urban areas, where most of the CSN sites are located, contributes to the overestimation of predicted trace metal concentrations. Work is currently underway to improve the representation of mixing during stable conditions in urban areas by including the heat retention due to impervious surfaces (e.g., pavement) in the WRF model.

While the model typically overestimates soil concentrations, there are several localized episodes during the summer, when soil concentrations are grossly underestimated by the model. Analysis suggests these observed elevated soil events are the result of long-range transport of dust from the African continent, and while the GEOS-Chem model simulation captures these events, the CMAQ modeling system has difficulty transporting the high soil concentrations from the boundary into the interior United States, which may be due to an overestimation of convective activity (e.g., precipitation) in the WRF model simulation that results in too much deposition. However, more analysis is needed to determine the exact cause of the underestimation of soil in the CMAQ model during these dust events.

In addition to the base model simulation, several model sensitivity simulations were also performed for the spring period to assess the impact of uncertainties in AFD emissions and natural WBD dust emission estimates on the model estimates of soil. As expected, removing the AFD emissions resulted in substantially lower model soil concentrations. Similarly, removing the effects of WBD emissions also lowered the model soil concentrations, but to a much lesser extent than removing the AFD emissions. Even with both AFD emissions and WBD effects removed, soil concentrations were still often overestimated, suggesting that there are other sources of errors in the modeling system that contribute to the overestimation of soil. In particular, other sources of trace elements in the emissions inventory are likely overestimated, such as emissions from EGUs or other industrial mineral/metal production processes. Efforts are currently underway to further improve the dust categories in the NEI, including possible adjustments to the seasonal and/or diurnal temporal profile of emissions.

\section{Supplementary material related to this article is available online at: http://www.geosci-model-dev.net/6/ 883/2013/gmd-6-883-2013-supplement.pdf.}

Acknowledgements. The authors would like to thank Lara Reynolds of Computer Sciences Corporation for performing the WRF model simulations used in this study. Thanks to Prakash Bhave for his contributions to this work, specifically for his help speciating $\mathrm{PM}_{\mathrm{other}}$ into the various trace elements and his many other suggestions along the way that contributed significantly to this project. Thanks also to Matt Landis and Gary Norris for providing and consulting on the continuous trace metal measurements from Dearborn.
Edited by: A. Lauer

Disclaimer. The United States Environmental Protection Agency through its Office of Research and Development supported the research described here. It has been subjected to Agency review and approved for publication.

\section{References}

Alexander, B., Park, R. J., Jacob, D. J., and Gong, S.: Transition metal-catalyzed oxidation of atmospheric sulfur: global implications for the sulfur budget, J. Geophys. Res., 114, D02309, doi:10.1029/2008JD010486, 2009.

Allen, D. J., Pickering, K. E., Pinder, R. W., Henderson, B. H., Appel, K. W., and Prados, A.: Impact of lightning-NO on eastern United States photochemistry during the summer of 2006 as determined using the CMAQ model, Atmos. Chem. Phys., 12, 1737-1758, doi:10.5194/acp-12-1737-2012, 2012.

Appel, K. W., Bhave, P. V., Gilliland, A. B., Sarwar, G., and Roselle, S. J.: Evaluation of the Community Multiscale Air Quality (CMAQ) model version 4.5: Sensitivities impacting model performance; Part II - particulate matter, Atmos. Environ., 42, 6057-6066, 2008.

Appel, K. W., Gilliam, R. C., Davis, N., Zubrow, A., and Howard, S. C.: Overview of the Atmospheric Model Evaluation Tool (AMET) v1.1 for evaluating meteorological and air quality models, Environ. Modell. Softw., 26, 434-443, 2011.

Bates, T. S., Quinn, P. K., Coffman, D., Schulz, K., Covert, D. S., Johnson, J. E., Williams, E. J., Lerner, B. M., Angevine, W. M., Tucker, S. C., Brewer, W. A., and Stohl, A.: Boundary layer aerosol chemistry during TexAQS/GoMACCS 2006: Insights into aerosol sources and transformation processes, J. Geophys. Res., 113, D00F01, doi:10.1029/2008JD010023, 2008.

Bey, I., Jacob, D. J., Yantosca, R. M., Logan, J. A., Field, B. D., Fiore, A. M., Li, Q., Liu, H. Y., Mickley, L. J., and Schultz, M. G.: Global modeling of tropospheric chemistry with assimilated meteorology: Model description and evaluation, J. Geophys. Res., 106, 23073-23096, 2001.

Byun, D. W. and Ching, J. K. S.: Science algorithms of the EPA models-3 Community Multiscale Air Quality (CMAQ) modeling system, EPA-600/R-99/030, 1999.

Byun, D. W. and Schere, K. L.: Review of the governing equations, computational algorithms, and other components of the models3 Community Multiscale Air Quality (CMAQ) modeling system, Appl. Mech. Rev., 59, 51-77, 2006.

EPA: SPECIATE 4.0: Speciation database development documentation final report, EPA/600/R-06/161, available at: http://www.epa.gov/ttn/chief/software/speciate/speciate4/

documentation/speciatedoc_1206.pdf (last access: 1 July 2013), 2006.

Etyemezian, V., Ahonen, S., Nikolic, D., Gillies, J., Kuhns, H., Gillette, D., and Veranth, J.: Deposition and removal of fugitive dust in the arid southwestern United States: measurements and model results, J. Air Waste Manage. Assoc., 54, 1099-1111, 2004.

Fairlie, T. D., Jacob, D. J., and Park, R. J.: The impact of transpacific transport of mineral dust in the United States, Atmos. Environ., 41, 1251-1266, 2007. 
Foley, K. M., Roselle, S. J., Appel, K. W., Bhave, P. V., Pleim, J. E., Otte, T. L., Mathur, R., Sarwar, G., Young, J. O., Gilliam, R. C., Nolte, C. G., Kelly, J. T., Gilliland, A. B., and Bash, J. O.: Incremental testing of the Community Multiscale Air Quality (CMAQ) modeling system version 4.7, Geosci. Model Dev., 3, 205-226, doi:10.5194/gmd-3-205-2010, 2010.

Fountoukis, C. and Nenes, A.: ISORROPIA II: a computationally efficient thermodynamic equilibrium model for $\mathrm{K}^{+}$. $\mathrm{Ca}^{2+}-\mathrm{Mg} 2+-\mathrm{NH}_{4}^{+}-\mathrm{Na}^{+}-\mathrm{SO}_{4}^{2-}-\mathrm{NO}_{3}^{-}-\mathrm{Cl}^{-}-\mathrm{H}_{2} \mathrm{O}$ aerosols, Atmos. Chem. Phys., 7, 4639-4659, doi:10.5194/acp-7-4639-2007, 2007.

Gilliam, R. C., Godowitch, J. M., and Rao, S. T.: Improving the horizontal transport in the lower tropospher with four dimensional data assimilation, Atmos. Environ., 53, 186-201, doi:10.1016/j.atmosenv.2011.10.064, 2012.

Ginoux, P., Chin, M., Tegen, I., Prospero, J. M., Holben, B., Dubovik, O., and Lin, S. J.: Sources and distributions of dust aerosols simulated with the GOCART model, J. Geophys. Res., 106, 20255-20273, 2001.

Hand, J. L., Copeland, S. A., Day, D. E., Dillner, A. M. Indresand, H., Malm, W. C., McDade, C. E., Moore, C. T., Pitchford, M. L., Schichtel, B. A., and Watson, J. G.: Spatial and seasonal patterns and temporal variability of haze and its constituents in the United States, Report V, available at: http://vista.cira.colostate.edu/improve/Publications/ Reports/2011/PDF/IMPROVE_V_FullReport.pdf (last access: 1 July 2013), 2011.

Houyoux, M. R., Vukovich, J. M., Coats Jr., C. J., Wheeler, N. J. M., and Kasibhatla, P.: Emission inventory development and processing for the seasonal model for regional air quality, J. Geophys. Res., 105, 9079-9090, 2000.

Iacono, M. J., Delamere, J. S., Mlawer, E. J., Shephard, M. W., Clough, S. A., and Collins, W. D.: Radiative forcing by long-lived greenhouse gases: Calculations with the AER radiative transfer models, J. Geophys. Res., 113, D13, D13103, doi:10.1029/2008JD009944, 2008.

Indresand, H. and Dillner, A. M.: Experimental characterization of sulfur interference in IMPROVE aluminum and silicon XRF data, Atmos. Environ., 61, 140-147, doi:10.1016/j.atmosenv.2012.06.079, 2012.

Kain, J. S.: The Kain-Fritsch convective parameterization: An update, J. Appl. Meteor., 43, 170-181, 2004.

Makar, P. A., Gravel, S., Chirkov, V., Strawbridge, K. B., Froude, F., Arnold, J., and Brook, J.: Heat flux, urban properties, and regional weather, Atmos. Environ., 40, 2750-2766, 2006.

Malm, W. C. and Hand, J. L.: An examination of the physical and optical properties of aerosols collected in the IMPROVE program, Atmos. Environ., 41, 3407-3427, 2007.

Malm, W. C., Sisler, J. F., Huffman, D., Eldred, R. A., and Cahill, T. A.: Spatial and seasonal trends in particle concentration and optical extinction in the United States, J. Geophys. Res., 99, 13471370, 1994

Martin, R. L. and Good, T. W.: Catalyzed oxidation of sulfur dioxide in solution: the iron-manganese synergism, Atmos. Environ., 25A, 2395-2399, 1991.

Morrison, H., Thompson, G., and Tatarskii, V.: Impact of cloud microphysics on the development of trailing stratiform precipitation in a simulated squall line: Comparison of one- and two-moment schemes, Mon. Weather Rev., 137, 991-1007, 2009.
Nenes, A., Pandis, S. N., and Pilinis, C.: ISORROPIA: A new thermodynamic equilibrium model for multiphase multicomponent inorganic aerosols, Aquat. Geochem., 4, 123-152, 1998.

Nenes, A., Pandis, S. N., and Pilinis, C.: Continued development and testing of a new thermodynamic aerosol module for urban and regional air quality models, Atmos. Environ., 33, 15531560, 1999.

Otte, T. L. and Pleim, J. E.: The Meteorology-Chemistry Interface Processor (MCIP) for the CMAQ modeling system: updates through MCIPv3.4.1, Geosci. Model Dev., 3, 243-256, doi:10.5194/gmd-3-243-2010, 2010.

Pace, T. G.: Methodology to Estimate the Transportable Fraction (TF) of Fugitive Dust Emissions for Regional and Urban Scale Air Quality Analyses, US EPA, Research Triangle Park NC, available at: http://www.epa.gov/ttnchie1/emch/ dustfractions/transportable_fraction_080305_rev.pdf (last access: 1 July 2013), 2005.

Pancras, J. P., Landis, M. S., Norris, G. A., Vedantham, R., and Dvonch, J. T.: Source apportionment of ambient fine particulate matter in Dearborn, Michigan, using hourly resolved PM chemical composition data, Sci. Total Environ., 448, 2-13, doi:10.1016/j.scitotenv.2012.11.083, 2013.

Park, R. J., Jacob, D. J., Kumar, N., and Yantosca, R. M.: Regional visibility statistics in the United States: Natural and transboundary pollution influences, and implications for the Regional Haze Rule, Atmos. Environ., 40, 5405-5423, 2006.

Perry, K. D., Cahill, T. A., Eldred, R. A., Dutcher, D. D., and Gill, T. E.: Long-range transport of North African dust to the eastern United States, J. Geophys. Res., 102, 11225-11238, 1997.

Pleim, J. E.: A combined local and nonlocal closure model for the atmospheric boundary layer. Part I: model description and testing, J. Appl. Meteor. Clim., 46, 1383-1395, 2007a.

Pleim, J. E.: A combined local and nonlocal closure model for the atmospheric boundary layer. Part II: application and evaluation in a mesoscale meteorological model, J. Appl. Meteor. Clim., 46, 1396-1409, 2007b.

Pleim, J. E. and Xiu, A.: Development and testing of a surface flux and planetary boundary layer model for application in mesoscale models, J. Appl. Meteor., 34, 16-32, 1995.

Pouliot, G., Simon, H., Bhave, P., Tong, D., Mobley, D., Pace, T., and Pierce, T.: Assessing the anthropogenic fugitive dust emission inventory and temporal allocation using an updated speciation of particulate matter, International Emission Inventory Conference, San Antonio, TX, September 27-30, available at: http://www.epa.gov/ttn/chief/conference/ei19/session9/ pouliot.pdf, 2010.

Reff, A., Bhave, P. V., Simon, H., Pace, T. G., Pouliot, G. A., Mobley, J. D., and Houyoux, M.: Emissions Inventory of $\mathrm{PM}_{2.5}$ Trace Elements across the United States, Environ. Sci. Technol., 43, 5790-5796, 2009.

Sarwar, G., Fahey, K., Kwok, R., Roselle, S. J., Mathur, R., Xue, J., Yu, J., and Carter, W. P. L.: Potential impacts of two $\mathrm{SO}_{2}$ oxidation pathways on regional sulfate concentrations: aqueousphase oxidation by $\mathrm{NO}_{2}$ and gas-phase oxidation by Stabilized Criegee Intermediates, Atmos. Environ., 68, 186-197, 2013.

Simon, H., Beck, L, Bhave, P. V., Divita, F., Hsu, F., Hus, Y., Luecken, D., Mobley, J. D., Pouliot, G., Reff, A., Sarwar, G., and Strum, M.: The development and uses of EPA's SPECIATE database, Atmos. Poll. Res., 1, 196-206, 2010. 
Skamarock, W. C., Klemp, J. B., Dudhia, J., Gill, D. O., Barker, D. M., Duda, M. G., Huang, X-Y, Wang, W., and Powers, J. G.: A description of the advanced research WRF version 3. NCAR Tech Note NCAR/TN 475 STR, 125 pp., available from UCAR Communications, P.O. Box 3000, Boulder, CO 80307, 2008.

Sokolik, I. N. and Toon, O. B.: Direct radiative forcing by anthropogenic airborne mineral aerosols, Nature, 381, 681-683, 1996.

Solomon, P. A., Klamser-Williams, T., Egeghy, P. P., Crumpler, D., Rice, J., Ashbaugh, L., and McDade, C.: Multi-site comparison of mass and major chemical components obtained by collocated STN and IMPROVE chemical speciation network monitors, presented at American Association for Aerosol Research 2004 Annual Conference, Atlanta, GA, 4-8 October, 2004.

Swall, J. and Foley, K. M.: The impact of spatial correlation and incommensurability on model evaluation, Atmos. Environ., 43, 1204-1217, 2009.

Tong, D. Q., Dan, M., Wang, T., and Lee, P.: Long-term dust climatology in the western United States reconstructed from routine aerosol ground monitoring, Atmos. Chem. Phys., 12, 5189-5205, doi:10.5194/acp-12-5189-2012, 2012.

Veranth, J. M., Pardyjak, E. R., and Seshadri, G.: Vehicle-generated fugitive dust transport: analytic models and field study, Atmos. Environ., 37, 2295-2303, 2003.
Vukovich, J. and Pierce, T.: The Implementation of BEIS3 within the SMOKE Modeling Framework, In Proceedings of the 11th International Emissions Inventory Conference, Atlanta, Georgia, 15-18 April, available at: www.epa.gov/ttn/chief/conference/ ei11/modeling/vukovich.pdf, 2002.

Walcek, C. J. and Tyalor, G. R.: A theoretical method for computing vertical distributions of acidity and sulfate production with cumulus clouds, J. Atmos. Sci., 43, 339-355, 1986.

Watson, J. G. and Chow, J. C.: Reconciling urban fugitive dust emissions inventory and ambient source contribution estimates: Summary of current knowledge and needed research, DRI document (6110.4), 240, available at: www.epa.gov/ttn/chief/efdocs/ fugitivedust.pdf, 2000.

Xiu, A. and Pleim, J. E.: Development of a land-surface model. Part I: application in a mesoscale meteorological model, J. Appl. Meteor., 40, 192-209, 2001.

Yarwood, G., Roa, S., Yocke, M., and Whitten, G.: Updates to the carbon bond chemical mechanism: CBo5. Final report to the US EPA, RT-0400675, available at: http://www.camx.com, http: //www.camx.com/publ/pdfs/cb05_final_report_120805.aspx (last access: 1 July 2013), 2005.

Zender, C. S., Bian, H., and Newman, D.: Mineral Dust Entrainment and Deposition (DEAD) model: Description and 1990s dust climatology, J. Geophys. Res., 108, 4416, doi:10.1029/2002JD002775, 2003. 